Anat. Inst. (Vorstand: Prof. M. SEKI) und ehem. Embryol. Abt.

(Leiter: Emerit. Prof. J. SHIKINAMI) d. Med. Fak., Univ. Okayama.

\title{
Über das früheste Stadium der Entwicklung der Zähne des Menschen.
}

\author{
人の㞀牙の発生の最初期飞就いて。
}

Gaiji KAGAWA 不川沉二.

(Eingegangen am 28. Juni 1956.)

Über die Entwicklung der Zähne des Menschen gibt es von alters her viele Forschungen, z. B. die von RÖSE (1891), von ORBAN (1927) und anderen. Besonders hat RÖSE an Rekonstruktionsmodellen genaue Beobachtungen angestellt. In Japan hat WATANABE (1937) am Unterkiefer von Föten besonders die Beziehung der Entwicklung der Zähne mit der Bildung der Alveolen untersucht. Es gibt aber noch viel Unklares besonders bezgl. der Beziehung der sich in der Zahnreihe entwickelnden Zähne zu einander, der Beziehung der Zähne mit dem umgebenden Gewebe und der Durchbruchsmechanismus. Vor Kurzem hat KATO (1953) seine Aufmerksamkeit der früheren Entwicklung der Zähne, besonders dem Entstehungsmechanismus der Zahnleiste und der Lippenfurchenleiste zugewandt.

Ich habe nun Untersuchungen über die frühere Entwicklung der Zähne vorgenommen und einige neue Kenntnisse gewonnen, deren Ergebnisse im folgenden mitgeteilt werden sollen.

\section{Material und Methode.}

Die Feststellung des Alters von Föten geschah nach der ScheitelSteißlänge. Das Material ist in Tabelle 1 zusammengestellt. Die Föten wurden in der ZENKER-Flüssigkeit oder im 10\%igen Formalin fixiert und in toto mit Boraxkarmin gefärbt. Sie wurden dann meistens in Paraffin, die größeren aber in Celloidin eingebettet. Es wurden die nötigen Teile in den Frontal-, Sagittal- und Querschnitten 100mal vergrößert aufs Papier abgezeichnet. Diese Abzeichnungen wurden auf Wachsplatten aufgeklebt, abgeschnitten und geschichtet und so ein Rekonstruktionsmodell hergestellt.

Die Breite der Zahuleiste wurde an den Schnitten an ihrem Anfangsteil gemessen. Als die größte Entfernung der Zahnleisten der beiden Seiten bezeichnete man den Abstand zwischen den äußeren Flächen des Anfangsteils der Zahnleisten. In späteren Stadien, in welchen die distalen Enden der Zahnleisten nach der Wangenseite gehogen waren, geschah die Messung der Eutfernung proximal von der Biegungsstelle. 
Tabelle 1.

\begin{tabular}{|c|c|c|}
\hline \multicolumn{2}{|c|}{$\begin{array}{c}\text { Stadium u. Nummer } \\
\text { d. Föten } \\
\end{array}$} & \multirow{2}{*}{$\begin{array}{c}\begin{array}{c}\text { Scheitel- } \\
\text { steiß- } \\
\text { länge (mm) }\end{array} \\
\begin{array}{c}7.5 \\
9.0\end{array}\end{array}$} \\
\hline 1. Stadium. & $\begin{array}{l}\text { Nr. } 13 \\
\text { Nr. } 16\end{array}$ & \\
\hline 2. Stadium. & $\begin{array}{l}\text { Nr. } 15 \\
\text { Nr. } 14\end{array}$ & $\begin{array}{l}10.0 \\
12.5\end{array}$ \\
\hline 3. Stadium. & $\begin{array}{l}\text { Nr. } 23 \\
\text { Nr. } 18\end{array}$ & $\begin{array}{l}16.0 \\
16.5\end{array}$ \\
\hline 4. Stadium. & $\begin{array}{ll}\text { Nr. } & 1 \\
\text { Nr. } & 2\end{array}$ & $\begin{array}{l}17.0 \\
18.0\end{array}$ \\
\hline 5. Stadium. & $\begin{array}{l}\text { Nr. } 19 \\
\text { Nr. } 9\end{array}$ & $\begin{array}{l}19.5 \\
20.0\end{array}$ \\
\hline 6. Stadium. & $\begin{array}{l}\text { Nr. } 17 \\
\text { Nr. } 51\end{array}$ & $\begin{array}{l}22.5 \\
23.0\end{array}$ \\
\hline 7. Stadium. & $\begin{array}{l}\text { Nr. } 21 \\
\text { Nr. } 60\end{array}$ & $\begin{array}{l}30.0 \\
31.0\end{array}$ \\
\hline 8. Stadium. & $\begin{array}{l}\text { Nr. } 40 \\
\text { Nr. } 38\end{array}$ & $\begin{array}{l}32.0 \\
35.0\end{array}$ \\
\hline 9. Stadium. & $\begin{array}{l}\text { Nr. } 4 \\
\text { Nr. } 11\end{array}$ & $\begin{array}{l}40.0 \\
41.0\end{array}$ \\
\hline 10. Stadium. & $\begin{array}{l}\text { Nr. } 30 \\
\text { Nr. } 8\end{array}$ & $\begin{array}{l}55.0 \\
56.0\end{array}$ \\
\hline
\end{tabular}

\section{Ergebnisse.}

Stadium 1. Nr. 13 (Scheitelsteißlänge $7.5 \mathrm{~mm}$ ) und $\mathrm{Nr}$. 16 (Scheitelsteißlänge $9 \mathrm{~mm}$ ).

Im lockeren Bindegewebe unter dem Deckepithel der Mundhöhle sieht man stellenweise Blutgefäße und Nerven. Der MECKELsche Knorpel kommt noch nicht vor, ebenso wenig Zahnanlagen.

Stadium 2. Nr. 15 (Scheitelsteißlänge $10 \mathrm{~mm}$ ) und $\mathrm{Nr}$. 14 (Scheitelsteißlänge $12.5 \mathrm{~mm}$ ).

Beim $10 \mathrm{~mm}$ und $12.5 \mathrm{~mm}$ langen Fötus beginnt im Unterkiefer ein Teil des Deckepithels der Mundhöhle sich als die erste Anlage der Zahnleiste zu verdicken (Abb. 1. und Tafelabb. 1), aber im Oberkiefer noch nicht. In dem Re-

konstruktionsmodell (Tafelabb. 1) sieht man, daß die Zahnleiste nicht über die ganze Ausdehnung des Kieferbogens, sondern nur an dem Teil, wo in Zukunft Molaren erscheinen sollen, zutagekommt. Nach der Medi-

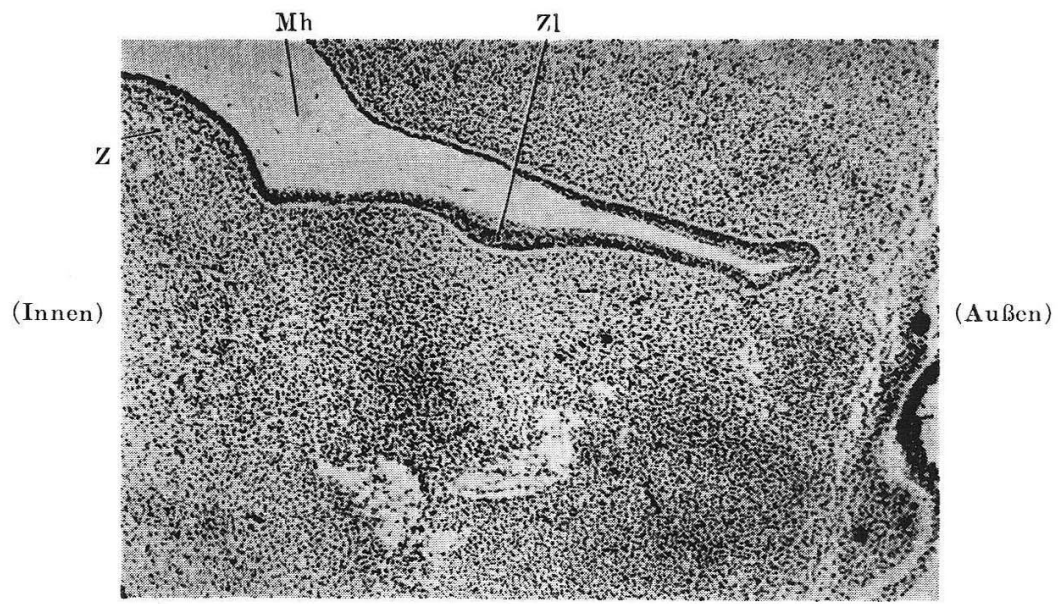

Abb. 1. Fötus von $10 \mathrm{~mm}$ Scheitelsteißänge. Frontalschnitt. Mh Mundlı̈̆lle, Z Zunge, Zl Zahnleiste. 100 K. 
anebene hin wird die Zahnleiste niedriger und versehwindet.

Die größte Entfernung zwischen den beiden Zahnleisten beträgt beim $10 \mathrm{~mm}$ langen Fötus $1.10 \mathrm{~mm}$ und beim $12.5 \mathrm{~mm}$ langen $1.29 \mathrm{~mm}$.

Stadium 3. Nr. 23 (Scheitelsteißlänge $16 \mathrm{~mm}$ ) und $\mathrm{Ar}$. 18 (Scheitelsteißlänge $16.5 \mathrm{~mm}$ ).

Das vordere Ende des MECKELschen Kinorpels erreicht noch nicht die Medianebene. Auf der äußeren Seite seines hinteren Teils sieht man zwei Nerven, die sich dahinter zu dem Nervus mandibularis vereinigen. Im Unterkicfer hat sich das Knochengewebe entwickelt, auch die Zungenanlage hat sich vergrößert. Hinten findet sich die Zungenknochenanlage aus dicht gedrängten Zellen. Die Anlagen der Glandula submandibularis, sublingualis und parotis kommen erst in diesem Stadium zum Vorschein.

Im Unterkiefer erscheint in diesem Stadium die Zahnleiste auch am Vorderzahnteil, wie sie vorher am Molarenteil gesehen wurde (Abb. 2),

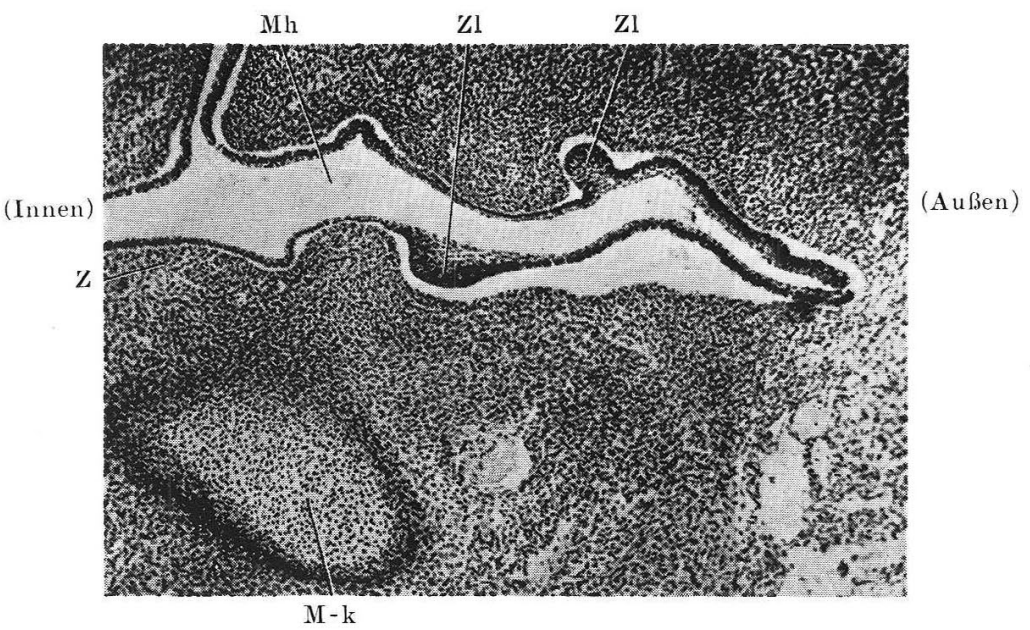

Abb. 2. Fötus von $16 \mathrm{~mm}$ Scheitelsteißlänge. Frontalschnitt. M-k MECKELscher Knorpel, Mh Mundhöhle, Zl Zahnleiste. $100 \times$.

und sie verbindet sich mit derjenigen der anderen Siite an der Medianebene (Tafelabb. 2). Im Oberkiefer entsteht eine niedrige Zahnleiste über den ganzen Kieferbogen hin. Die Zahnleiste im Oberkiefer ist breiter, aber niedriger als im Unterkiefer (Tafelabb. 3).

Die Zahuleiste kommt derart aus dem Epithel hervor, daß sie sich nach innen neigt (Tafelabb. 3). Die Neigung ist im Oberkiefer stärker als im Unterkiefer, und am Molarenteil stärker als am Vorderzahnteil.

Die Entfernung der beiden Zahnleisten ist im Oberkiefer grölere als im Dnterkiefer. Daher befinden sich die boden Zahuleisten des Oberkiefers 
mehr lateral als diejenigen des Unterkiefers. Die größte Entfernung der beiden Zahnleisten beträgt beim $16 \mathrm{~mm}$ langen Fötus im Oberkiefer $1.62 \mathrm{~mm}$ und im Unterkiefer $1.3 \mathrm{~mm}$ und beim $16.5 \mathrm{~mm}$ langen im Oberkiefer 1.63 $\mathrm{mm}$ und im Unterkiefer $1.33 \mathrm{~mm}$.

Der Saum der Zahnleiste zeigt sich am medialen Vorderzahnteil des Unterkiefers wellenartig (Tafelabb. 2), und man zählt 4 Vorsprünge, welche die andeutenden Zahnkeime der Schneidezähne darstellen. Das Epithel des Keimes des 1. Schneidezahns hat sich lingualwärts (d. h. auf der hinteren Seite) gewuchert (Tafelabb. 2), was als die Andeutung des ACKEKKNECH'Tschen Organs anzunehmen ist. An der Zahnleiste des Oberkiefers wird aber ein solches Gebilde nicht gesehen.

An dem Teil, wo später Eckzähne und Molaren sitzen sollen, ist das Epithel auf der labialen Seite der Zahnleiste in das Bindegewebe hineingewachsen, so daß die Lippenfurchenleiste gebildet worden ist (Abb. 3).

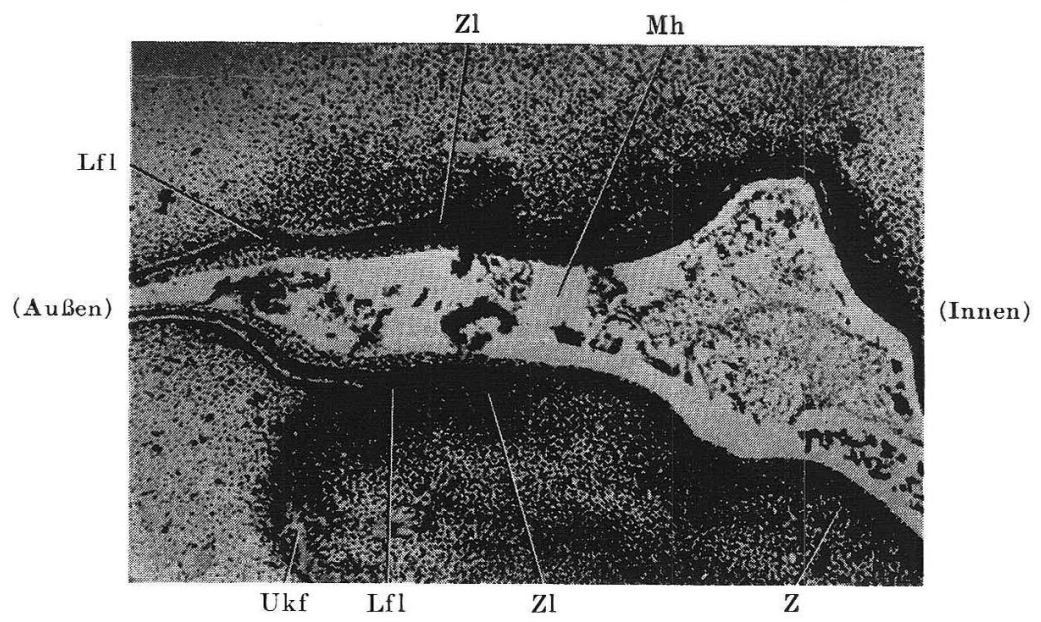

Abb. 3. Fötus von $16.5 \mathrm{~mm}$ Scheitelsteißlänge. Frontalschnitt. Lfl Lippenfurchenleiste, Mh Mundhöhle, Ukf Unterkiefer, ZI Zahnleiste. $100 \times$.

Diese Leiste ist niedriger als die Zahnleiste, aber in der labiolingualen Richtung an Dicke überlegen. Ihre Zellen sind etwas lockerer vorhanden als die der Zahnleiste.

Stadium 4. Nr. 1 (Scheitelsteißlänge $17 \mathrm{~mm}$ ) und Nr. 2 (Scheitelsteißlänge $18 \mathrm{~mm}$ ).

In diesem Stadium hat die Verknöcherung des Kieferknochens in der Kinngegend, in welcher sich der Nervus mandibularis verzweigt, begonnen, was sich an den Schnitten als eine Knochenplatte erkennen läßt. Auch ist der MECKELsche Knorpel zu sehen. Die Anlage der Subman- 
dibulardrüse ist etwas vergrößert. Der Ausführungsgang der Sublingualdrüse ist ein bischen verlängert. Die Anlage der Parotisdrüse zeigt sich an ihrem knde angeschwollen, um die Bildung des Drüsenkörpers za beginnen.

Die Zahnleiste neigt sich nun mehr als im vorigen Stadium. welche Neigung im Oberkiefer stärker ist als im Unterkiefer und in den beiden Kiefern am Molarenteil stärker ist als am Vorderyahnteil (Abb. 4).

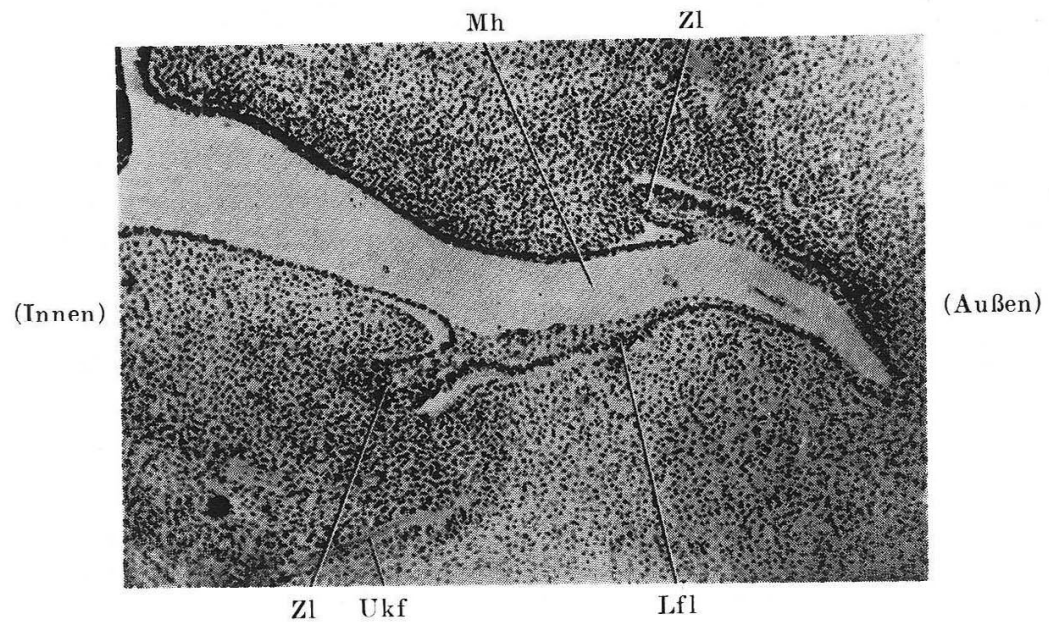

Abb, 4. Fötus von $17 \mathrm{~mm}$ Scheitelsteißlänge. Frontalschnitt. Die Zahnleiste der beiden Kiefer neigt sich nach der Zungenseite. Lfl Lippenfurchenleiste, Mh Yundhöhle, Zl Zahnleiste. $100 \times$.

Nun sind die Keime der Schneidezähne, die im vorigen Stadium an der Zahnleiste des Unterkiefers entstanden sind, noch kenntlicher geworden (Tafelabh. 4). Auch an der Zahnleiste des Oberkiefers erschienen vier Keime der Schneidezähne. Die Zahnleiste des Oberkiefers ist am Molarenteil höher als am Schneidezahnteil (Tafelabb. 5). Bei den 17 und $18 \mathrm{~mm}$ langen Föten sind also an den beiden Kiefern acht Zahnkeime erschienen.

Der an das ACKFRKNECHTsche Organ errinnernde halb kugelige Vorsprung läßt sich hinter dem ersten Schneidezahn beobachten (Tafelabb. 4). Seine Zellen sind etwas lockerer vorhanden als in der Zahnleiste.

Die größte Entfernung zwischen den beiden Zahnleisten beträgt beim $17 \mathrm{~mm}$ langen Fötus im Oberkiefer $1.71 \mathrm{~mm}$ und im Unterkiefer $1.40 \mathrm{~mm}$ und beim $18 \mathrm{~mm}$ langen im Oberkiefer $1.92 \mathrm{~mm}$ und im Unterkiefer 1.65 $\mathrm{mm}$.

Die Lippenfurchenleiste des Unterkiefers des $18 \mathrm{~mm}$ langen Fötus wird vorn vom Eckzahnteil an allmählich niedriger, um endlich zu verschwinden. Hinten läuft, sie eine Weile der Zahnleiste entlang und ver- 
schwindet dann, ohne daßs sie sich wie die Zahnleiste am Fnde bucealwärts verbiegt. Auch im Oberkiefer reigt sich die Lippenfurchenleiste. Die Zahnleiste neigt sich in Querschnitten immer lingualwärts hin, aber die Lippenfurchenleiste nicht. Diese ist ïbrigens nierleiger als jeme.

Stadium 5. Nr. 19 (Sicheitelsteilö̈̈nge $19.5 \mathrm{~mm}$ ) und Nr. 9 (Scheitelsteißlänge $20 \mathrm{~mm}$ ).

Die Entwicklung des Kieferknochens ist in einem weit stäskeren Grade fortgeschriten als im vorigen Stadium. Die Anlage des Interkieferknothens ist in den Frontalsshnitten von V-Form mit der Öftnung nach oben und außen. Im Oherkiefer reigt sich an der Gegend des Eckzahns und des ersten Molars eine Verknöcherung. Der MECKEI-Knorpel läıft von hinten nach vorn. Sein vorderes Ende verschwindet allmählich. Unter den Speicheldrïsen hat die Parotisdrüse ihren Ausführungsgang verlängert und ihren Drüsenkörper vergrößert. Anch die Jrïsenkörper der Submandibularund Sublingualdrise sind etwas größer geworden.

Beim $20 \mathrm{~mm}$ langen Fötus hat die /ahnleiste an Höhe gewonnen, ihre Neigung nach innen ist auch stärker geworden. Im Oberkiefer kommt der Keim des Wckzahns distal am schon entstandenen Schneidezahnkeim hervor (Abb. 5 und Tafelabb. 7). Der Abstand zwischen den Zahnkeimen ist fast

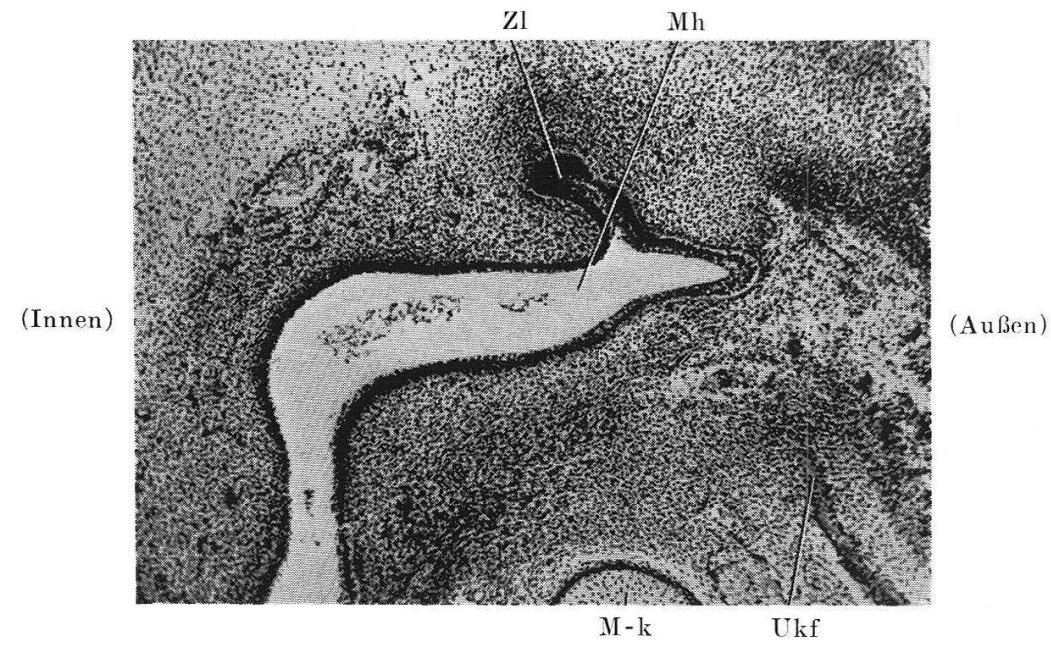

Abb. 5. Fötus von $20 \mathrm{~mm}$ Scheitelsteißlänge. Frontalschnitt. Mh Mundhöhle M-k MECKELscher Knorpel, Ukf Unterkiefer, Zl Zahnleiste. $100 \times$.

gleich. Im Unterkiefer sieht man dagegen noch keine Zahnkeime (Tafelabb. 6). Die Zahnkeime zeigen alle die Neigung, schräg von der Zahnleiste nach der labialen Seite hin zu wachsen. 
Das ACKERKNECHTeche Organ befindet sich brim $20 \mathrm{~mm}$ langen Fötus als ein dentiches, halbkugliges Gebilde auf den beiden seiten der Medialebene hinter der Zahnleiste (Tafelabb. (6).

Die Lippenfurchenleiste entwickelt sich im Oberkiefer am Molarenteil. besonders am 1. Molarenteil am besten, im Vnterkiefer aber am Eckzahnteil.

Dis größte Entfernung der beiden Zahnleisten beträgt beim $19.5 \mathrm{~mm}$ langen Fötus am Oberkiefer $19.5 \mathrm{~mm}$ und am Unterkiefer $16.9 \mathrm{~mm}$ und beim $20 \mathrm{~mm}$ langen Fötus am Oberkiefer $2.13 \mathrm{~mm}$ und am Unterkiefer $1.8 \mathrm{~mm}$.

Stadium 6. Nr. 17 (Scheitelsteißlïnge $22.5 \mathrm{~mm}$ ) und Nr. 51. (Scheitelsteißlänge $23 \mathrm{~mm}$ ).

Der stahförmige MECKELsche Knorpel läuft von hinten nach vorn, und sein lindteil krümmt sich an der Medialebene nach hinten. Der Unterkieferknochen bildet an Frontalschnitten eine V-Form mit der Öffnung nach oben. Die Speicheldrüsen entwickeln sich stärker als vorher. Unter ihnen ist die Submandbulardrüse die größte.

Beim Fötus von $23 \mathrm{~mm}$ Länge entstehen im Unterkiefer die Keime des Eckzahns und des ersten Molars distal am Schneidezahnkeim ('Tafelabb. 8).

Am ersten und zweiten Schneidezahnkeim kommt der Schmelzknoten zum Vorschein. Dieser fängt an, sich den kappenförmigen Ekzahnkeim zo bilden (Abh. 6).

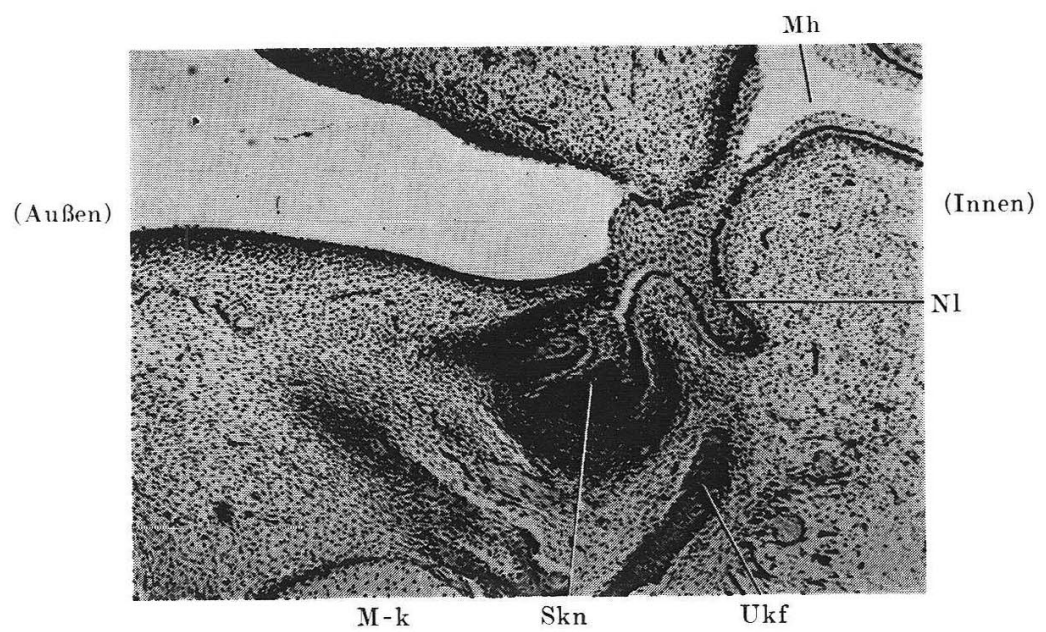

Abb. 6. Fötus von $23 \mathrm{~mm}$ Scheitelsteißlänge. Frontalschnitt. Mh Mundhöhle, $M-k$ MECKELscher Knorpel, $N l$ Nebenleiste, Skn Schmelzknoten, Ukf Unterkiefer. $100 \times$. 
Die Entwicklung des Wokzahnkeimes geht schnell vor sich. Wr ist schon größer als die anderen. Der erste Molarenkeim steht etwas entfernt von dem Eckzahnkeim ('Tafelahb. 8).

Der Sichmelzknoten sitzi an der Mitte des schüsselförmigen Zahnkeims. Seine Zellen sind im Vergleich zu denjenigen des Deckepithels der Mundhöhle und denjenigen im Inneren des Zahnkeimes kleiner und dichter ged rängt, vorhanden.

Das ACKERKNECHTsche Organ bleibt wie im letzten Stadium, und seine Zellen sind dichtged rängt (Tafelabb. 8).

Im Oberkiefer sind die Keime des ersten und zweiten Schneidezahns und des Eckzahns von Kappenform und haben den Schmelzknoten. Darunter ist der Eckzahnkeim am größten. Der Keim des ersten Molars ist. noch nicht zu sehen (Tafelabb. 9).

Die Neigung des Zahnkeims nach der labialen Seite ist am stïrksten am Wekzahnkeim des Oberkiefers.

Die größte Entfernung der beiden Zahnleisten beträgt beim $22.5 \mathrm{~mm}$ langen Embryo am Oberkiefer $2.82 \mathrm{~mm}$ und am Unterkiefer $1,82 \mathrm{~mm}$ und beim $23 \mathrm{~mm}$ langen Embryo am Oberkiefer $2.35 \mathrm{~mm}$ und am Unterkiefer $1.9 \mathrm{~mm}$.

Die Lippenfurchenleiste ist im Oberkiefer am Molarenteil deutlich zu sehen, aher vorn vom Eckzahnteil ab wird sie undeutlich. Im Unterkiefer ist sie aher auch vorn rom Eckzahnteil deutlich gebildet.

Stadium 7. Nr. 21 (Scheitelsteißlänge $30 \mathrm{~mm}$ ) und Nr. 60 (Scheitelsteißlänge $31 \mathrm{~mm}$ ).

Die Entwicklung des Unterkieferknochens und des MECKELschen Knorpels ist fortgeschritten. Die vorderen Enden der beiden Knorpel berühren sich miteinander und biegen sich nach hinten, wie man es schon im vorigen Stadium gesehen hat. Der Unterkieferknochen umarmt den MECKELschen Knorpel.

Beim Fötus von $30 \mathrm{~mm}$ Länge sind die Keime des ersten und des zweiten Schneidezahns, des Eckzahns und des ersten Molars von Kappenform und haben den Schmelzknoten. Unter ihnen ist der Eckzahnkeim am größten und dem Glockenform-Stadium nahe (Abb. 7). Die untere Saumfläche des kappenförmigen Eckzahnkeims wendet sich schräge nach außen und unten, die des Eckzahns ebenfalls nach außen und unten und die des ersten Molars nur ein wenig nach außen und unten. Der zweite Molarenkeim erscheint noch nicht (Tafelabb. 10).

Bei diesem Fötus ist die Zahnleiste des Unterkiefers hinter der ersten Molarenanlage etwa $30^{\circ}$ gegen die Wange zu gebogen und wird dann immer schmaler und rerschwindet (Tafelabb. 10).

Das ACKERKNECHT-Organ verkleinert sich und läßt nur noch seine Spur zurïck (Tafelabb. 10). 


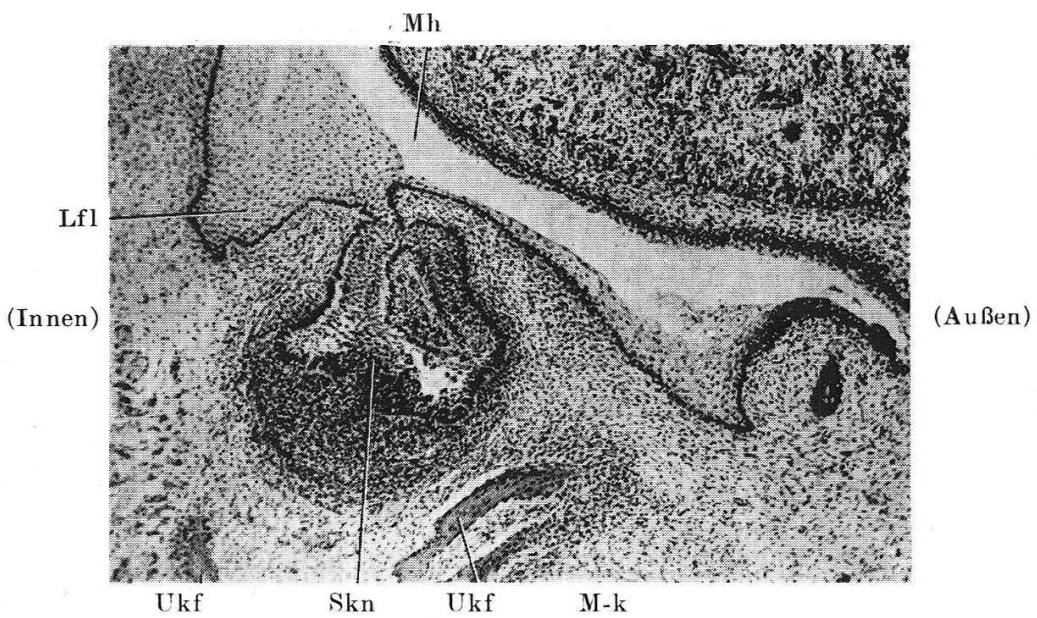

Abb. 7. Fötus von $30 \mathrm{~mm}$ Scheitelsteißlänge. Frontalschnitt. Lfl Lippenfurchenleiste, Mh Mundhöhle, M-k MECKELscher Knorpel, Skn Schmelzknoten, Ukf Unterkiefer, Zl Zahnleiste. $100 \times$.

Wendet man nun den Blick auf den Oberkiefer, so bemerkt man eine deutliche Entwicklung der Zahnkeime, die im vorigen Stadium nur einfache Zellenmassen darstellten. Besonders auffallend ist die Erscheinung des ersten Molarenkeims, der im vorigen Stadium noch nicht vorhanden war. Sechs Keime der Eck- und Schneidezähne haben alle schüsselförmiges Schmelzorgan bekommen, das in der Richtung proximodistal etwas länger, also in der Richtung buccolingual etwas schmäler ist, was sich durch Vergleich der Frontal-, Quer- und Sagittalschnitte miteinander bestätigte. Die Zahnkeime sind auf der buccalen Seite der Zahnleiste vorhanden (Tafelabb. 11). Darunter will sich nun der Eckzahnkeim von der Zahnleiste trennen.

Die zukünftige längere Achse des kappenförmigen Zahnkeims des Nittelschneidezahns richtet sich etwas schräg nach außen. Dasselbe gilt von den Keimen des Seitenschneide- und Eckzahns. Der Keim des zweiten Molars ist noch nicht von Kappenform.

Die größte Entfernung der beiden Zahnleisten ist beim $30 \mathrm{~mm}$ langen Fötus am Oberkiefer $3.21 \mathrm{~mm}$ und am Unterkiefer $2.21 \mathrm{~mm}$ und beim $31 \mathrm{~mm}$ langen Fötus am Oberkiefer $3.25 \mathrm{~mm}$ und am Unterkiefer $2.3 \mathrm{~mm}$.

Die Lippenfurchenleiste ist im Oberkiefer am Eckzahnkeim am höchsten und am Molarenkeim am niedrigsten. Dieses dammartige Gebilde ist auf der buccalen Seite jeden Zahnkeims ein wenig besser entwickelt. Dies ist auch im Unterkiefer der Fall, nur daß im Unterkiefer die Lippenfurchenleiste von den Zahnkeimen mehr entfernt gelegen ist. 
Stadium 8. Nr. 40 (Sicheitelsteißlïnge $32 \mathrm{~mm}$ ) und Nr. 38 (Scheitelsteißlänge $35 \mathrm{~mm}$ ).

1)er Unterkieferknohen, der den MECKkL-Knorpel umarmt, zeigt am Wrkzahnteil die größte Hntwicklung. Die kappenförmigen Zahnkeime des l'nterkiefers sind größer als im vorigen Stadium, ihre Schmelyknoten anch bedeutender (Tafelabb. 12). Man sieht die Anlage des zweiten Molars noch nicht. Der Eckzahnkeim ist im I'nterkiefer am größten, daran schlißt sich der erste Molarenkeim an.

Im Oberliefer ist der erste Molarenkeim im Kappenstadium, der zweite Molarenkeim ist aber noch nicht. zu sehen (Tafelabh. 13).

Die Zahnleiste wird in den beiden Kiefern hinter dem Eokzahnkeim etwas schmäler, und ist, wie im vorigen stadium, ein wenig nach außen gebogen.

Das ACKRRKNECHT-Organ lïßt sich nicht mehr bemerken.

Die größte Entfernung der beiden Zahnleisten beträgt beim $32 \mathrm{~mm}$ langen Fötus im Oberkiefer $2.31 \mathrm{~mm}$ und im Unterkiefer $2.40 \mathrm{~mm}$ und beim $35 \mathrm{~mm}$ langen Fötus im Oberkiefer $3.51 \mathrm{~mm}$ und im Unterkiefer 2.60 $\mathrm{mm}$.

Dje Lippenfurchenleiste ist wie im vorigen Stadium.

Stadium 9. Nr. 4 (Sicheitelsteißlänge $40 \mathrm{~mm}$ ) und Nr. 11 (Scheitelsteißlänge $41 \mathrm{~mm}$ ).

Das Gewebe des Cnterkieferknochens hildet sich am Eckzahnteil am stärksten. Der schüsselförmige Zahnkeim des ersten Schneidezahns im Unterkiefer des $40 \mathrm{~mm}$ langen Fötus will sich nun von der Zahnleiste abtrennen (Tafelabb. 14). Der Eckzahnkeim ist bedentend entwickelt. Der erste Molarenkeim zeigt unter den Zahnkeimen des Unterkiefers die höchste Entwicklung. Er ist der größte und ist ins Glockenstadium übergegangen. Der zweite Molarenkeim ist auch erschienen (Tafelabb. 14). Sein Hals, der ihn mit der Zahnleiste verbindet, ist länger als bei den anderen Zahnkeimen.

Man findet keine Spur rom ACKERKNECHT-Organ mehr.

Im Oberkiefer verlängert sich die Zahnleiste weit nach hinten. Nahe an ihrem hinteren Ende ist der zweite Molarenkeim angeschwollen (Abb. 8). Wie in Tafelabb. 15 gezeigt ist, stehen die Schneidezahnkeime im Glockenstadium. Die Entwicklung des zweiten Schneidezahnkeims, der jetzt von Glockenform ist, folgt der des ersten Schneidezahnkeims. Der Eckzahnkeim ist ebenfalls im Glockenstadium und im Oberkiefer am besten entwickelt. Der erste Milchmolar ist noch von Kappenform. Übrigens beginnt der zweite Molarenkeim sich zu bilden (Tafelabb. 15).

Die Zahnleiste ist am Beginn ihres Entstehens, wie erwähnt, nach innen geneig1. Es ist zu bemerken, daß in diesem Stadium die Neigung 


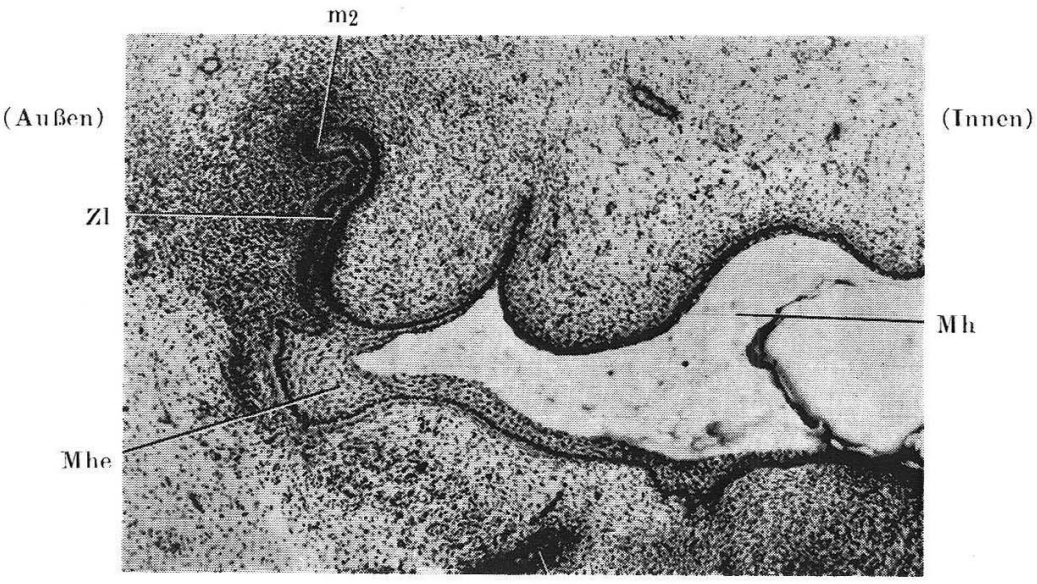

Ukf

Abb. 8. Fötus von $40 \mathrm{~mm}$ Scheitelsteißlänge. Frontalschnitt. Mh Mundhöhle, Mhe Mundhöhlenepithel, $m_{2}$ Keim des zweiten Molars, $Z l$ Zahnleiste. $100 \times$.

nachläßt, und daß der Randteil der Zahnleiste sich nach außen zu biegen anfängt (Tafelabb. 15 und 18), und zwar sowohl im Ober-wie im Unterkiefer. Der zweite Molarenkeim des Ober- und Unterkiefers erseheinen erst in diesem Stadium.

Die Biegung des hinteren Teils der Zahnleiste nach buccalwärts, die in vorigen Stadien vorhanden war, ist nun kaum zu sehen.

Die zukünftige Längsachse des Schmelzorgans der Schneidezähne des Oberkiefers ist ein wenig nach oben innen hingeneigt, die des Eckzahns aber ein wenig nach oben außen und die des ersten Molars nach oben. Diejenige der Eck- und Schneidezähne des Unterkiefers richtet sich nach unten, und die des ersten Molars nach unten und außen.

Die größte Entfernung der beiden Zahnleisten beträgt beim $40 \mathrm{~mm}$ langen Fötus im Oberkiefer $4.00 \mathrm{~mm}$ und im Unterkiefer $3.20 \mathrm{~mm}$ und beim $4.1 \mathrm{~mm}$ langen Embryo im Oberkiefer $4.10 \mathrm{~mm}$ und im Unterkiefer $3.20 \mathrm{~mm}$.

Die Lippenfurchenleiste ist wie im letzten Stadium auf der bucealen Seite jeden Zahnkeims etwas besser entwickelt, und ihr hinteres Ende liegt nahe an dem hinteren Ende der Zahnleiste. An den Rekonstruktionsmodellen nimmt man gewahr, daß die Lippenfurchenleiste neben den Keimen der Schneide- und Eckzähne tiefer reicht als die Zahnleiste, neben dem Eckzahn und den Molaren aber nicht so tief.

Stadium 10. Nr. 30 (Scheitelsteißlänge $55.0 \mathrm{~mm}$ ) und Nr. 8 (Scheitelsteißlänge $56.0 \mathrm{~mm}$ ).

Der von Knochengewebe bedeckte MECKELsche Knorpel ist auf dem 
Wege der Verknöcherung.

Im Unterkiefer des $56 \mathrm{~mm}$ langen Fötus trennen sich der erste und nweite Wokahnkeim von der bucealen Fläche der Zahnleiste ab (Tafelabb. 16). Der erste Molarenkeim ist auffallend grob und ist nun der größte im Unterkiefer (Ab). 9). Der zweite Molarenkeim ist kappenförmig und im

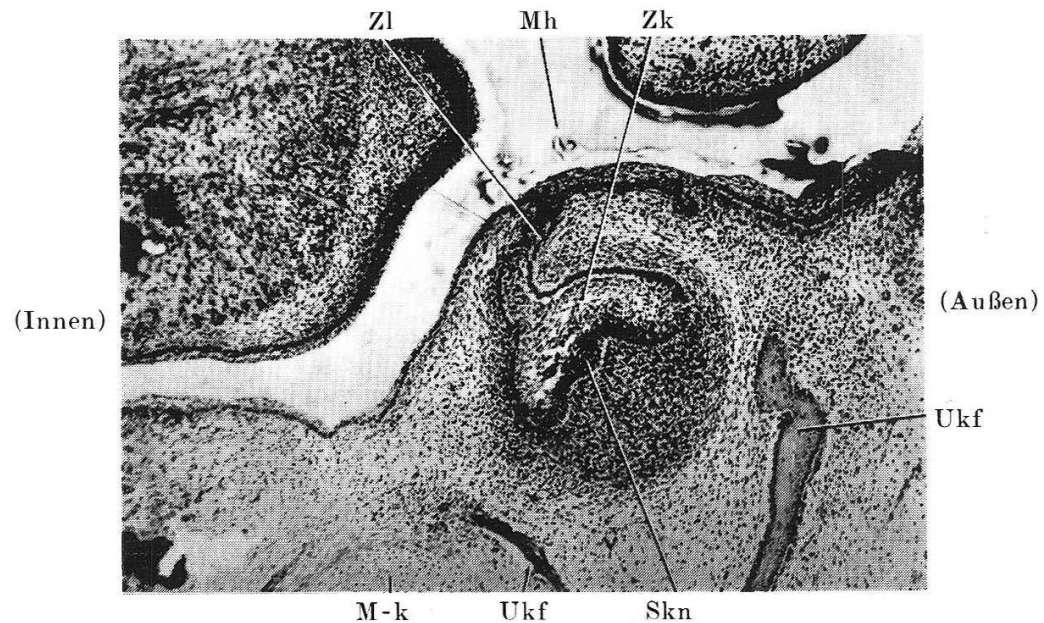

Abb. 9. Fötus von $56 \mathrm{~mm}$ Scheitelsteißlänge. Frontalschnitt. Mh Mundhöhle $M-k$ MECKELscher Knorpel, Skn Schmelzknoten, Uki Unterkiefer, Zl Zahnleiste. $100 \times$.

Vergleich zu demselben des Oberkiefers an der Fntwicklung verspätet.

Im Oberkiefer stehen die Keime des ersten und zweiten Schneidezahns und des Eckzahns zwischen dem Kappen- und Glockenstadium.

Bezüglich der Entwicklung der Zahnkeime im Oberkiefer steht der erste Molar an der zweiten Stelle, und der zweite Molar an der ersten ('Tafelabb. 17).

Die größte Entfernung der beiden Zahnleisten ist beim $55 \mathrm{~mm}$ langen Fötus im Oberkiefer $5.55 \mathrm{~mm}$ und im Unterkiefer $4.9 \mathrm{~mm}$ und beim $56 \mathrm{~mm}$ langen Fötus im Oberkiefer $5.61 \mathrm{~mm}$ und im Unterkiefer $5.01 \mathrm{~mm}$.

An der Lippenfurchenleiste ist kaum eine Verschiedenheit von dem im vorigen Stadium beschriebenen Zustand zu bemerken, nur daß sie am zweiten Molarenkeim bedeutend vorgesprungen ist. Der hintere Teil der Lippenfurchenleiste liegt nahe an der Zahnleiste und verschwindet allmählich, während die Zahnleiste plötzlich verschwindet. Auch im Unterkiefer ist dic Lippenfurchenleiste von fast gleichem Aussehen wie im vorigen Stadium. 


\section{Auswertung der Ergebnisse.}

a) Erste Entwicklung der Zahnleiste.

Die Zeit des Auftretens der ersten Anlage der Zahnleiste scheint individuell etwas verschieden zu sein. Z. B. bemerkte KOLLMANN (1907) sie erst am Anfang der 5. Woche, RösE (1893) beim 11-12 mm langen Fötus, angblich im Alter von etwa 34 Tagen, ferner ORBÁN (1928) beim 11-13 mm langen Fetus, MEYER (1932) beim 13-14 mm langen, WATANABE (1937) beim $13 \mathrm{~mm}$ langen und KATO (1953) beim $10 \mathrm{~mm}$ langen. Bei meinem Material erscheint sie schon beim $10 \mathrm{~mm}$ langen Fötus an dem späteren Molarenteil. Es konnte die von YAMAMURA beschriebene (1937) vorlaufende Zahnleiste nicht beobachtet werden.

b) Erstes Erscheinen der Zahnleiste.

Es erscheint am Molarenteil des Unterkiefers. Die beiden Zahnleisten verlängern sich nach vorn medial, um sich endlich miteinander zu verbinden. Der Befund weicht von dem von WATANABE (1939) beobachteten, wonach die Zahnleiste zuerst am Vorderzahnteil des Unterkiefers erscheint, und auch von dem von KATO (1953) beobachteten, wonach sie von dem Vorderzahn- und dem ersten Molarenteil ausgeht, ab.

\section{c) Die Frorm der Zahnleiste.}

Bald nach dem Erscheinen neigt sich die Zahnleiste sowohl im Oberwie im Unterkiefer lingualwärts. Die Neigung ist im Oberkiefer stärker als im Unterkiefer und in den beiden Kiefern am Molarenteil stärker als am Vorderzahnteil.

Beim $4.0 \mathrm{~mm}$ langen Föten nimmt diese Neigung ab. Der Randteil der Zahnleiste biegt sich dann buccalwärts, worauf anscheinend bis jetzt niemand aufmerksam gemacht hat.

Der hintere Teil der Zahnleiste des Unterkiefers wendet sich am Molarenteil nach der Wange hin und zwar mit dem Winkel von weniger als $30^{\circ}$, eine Tatsache, die anders ist als die Angaben im bisherigen Schrifttum, wonach die Wendung fast rechtwinklig ist. Der Wendungswinkel wird später beim $40-56 \mathrm{~mm}$ langen Fötus kleiner.

d) Die Entfernung der beiden Zahnleisten voneinander.

Die äußere Form der Zahnleiste ist, worauf auch RÖSE (1891) hingewiesen hat, im Oberkiefer größer als im Unterkiefer. Aber bisher findet sich keine genaue Messung der Entfernung der beiden Zahnleisten in der Literatur. Aus Tabelle 2 ersieht man, daß die Differenz der Größen zwischen dem Ober- und Unterkiefer bis aufs Kappenstadium nach und nach zunimmt, bis sie beim $30 \mathrm{~mm}$ langen Fötus mit dem Kappenstadium wieder abzunehmen anfängt. 
Tabelle 2. Die Entfernung der beiden Zahnleisten (mm).

\begin{tabular}{|c|c|c|c|}
\hline Stadium & $\begin{array}{l}\text { Scheitelsteiß- } \\
\text { länge (mm) }\end{array}$ & Unterkiefer & Oberkiefer \\
\hline 1. & $\begin{array}{l}7.5 \\
9.0\end{array}$ & & \\
\hline 2. & $\begin{array}{l}10.0 \\
12.5\end{array}$ & $\begin{array}{l}1.10 \\
1.29\end{array}$ & \\
\hline 3. & $\begin{array}{l}16.0 \\
16.5\end{array}$ & $\begin{array}{l}1.30 \\
1.33\end{array}$ & $\begin{array}{l}1.62 \\
1.63\end{array}$ \\
\hline 4. & $\begin{array}{l}17.0 \\
18.0\end{array}$ & $\begin{array}{l}1.40 \\
1.65\end{array}$ & $\begin{array}{l}1.71 \\
1.92\end{array}$ \\
\hline 5. & $\begin{array}{l}19.5 \\
20.0\end{array}$ & $\begin{array}{l}1.69 \\
1.80\end{array}$ & $\begin{array}{l}1.90 \\
2.13\end{array}$ \\
\hline 6. & $\begin{array}{l}22.5 \\
23.0\end{array}$ & $\begin{array}{l}1.82 \\
1.90\end{array}$ & $\begin{array}{l}2.32 \\
2.35\end{array}$ \\
\hline 7. & $\begin{array}{l}30.0 \\
31.0\end{array}$ & $\begin{array}{l}2.21 \\
2.30\end{array}$ & $\begin{array}{l}3.21 \\
3.25\end{array}$ \\
\hline 8. & $\begin{array}{l}32.0 \\
35.0\end{array}$ & $\begin{array}{l}2.40 \\
2.60\end{array}$ & $\begin{array}{l}3.31 \\
3.51\end{array}$ \\
\hline 9. & $\begin{array}{l}40.0 \\
41.0\end{array}$ & $\begin{array}{l}3.20 \\
3.20\end{array}$ & $\begin{array}{l}4.00 \\
4.10\end{array}$ \\
\hline 10. & $\begin{array}{l}55.0 \\
56.0\end{array}$ & $\begin{array}{l}4.90 \\
5.01\end{array}$ & $\begin{array}{l}5.55 \\
5.61\end{array}$ \\
\hline
\end{tabular}

e) Die Entstehung des Zahnkeimes.

Beim Fötus von $16-16.5 \mathrm{~mm}$ Länge kommt der Sichneidezahnkeim des Unterkiefers zum Vorschein. Wenn der Fötus 17-18 mm lang wird, treten im Oberkiefer 4 Schneidezahnkeime auf, es erscheinen also in beiden Kiefern 8 Keime. Die Entstehung aller Zahnkeime in den beiden Kiefern vollendet sich erst im Fötus von $40 \mathrm{~mm}$ Länge. Die Zeit ist später als die bei WATANABE (1935) angegebene, der schon im Fötus von $35 \mathrm{~mm}$ Länge sämtliche Zahnkeime vorfand. Soweit ich die Literatur übersehe, liegt bisher keine nähere Angabe über die Reihenfolge der Entstehung der Zahnkeim vor. Dieselbe ist in Tabelle 3 gezeigt.

Die Zahnkeime sitzen in frühen Stadien weder nach der äußeren noch nach der inneren Seite der Zahnleiste verschoben, aber sie nehmen im Kappenstadium des $21 \mathrm{~mm}$ langen Föten auf der lingualen Seite der Zahnleiste Platz.

lis ist angenommen worden, daß das Glockenstadium erst beim $100 \mathrm{~mm}$ langen Fötus am Mittelschneidezahnkeim anfange. Der Beginn des Clockenstadiums wurde aber in meinem Naterial sehon beim $30 \mathrm{~mm}$ langen fötus am Ekkzahn des linterkiefers beobachtet. 1th möchte hier noch der Beobachtung ron KITO (1954) gedenken, wonach das Glockenstadium bei cinem Fötus von $17.5 \mathrm{~mm}$ Jänge am 1. und 2. Schneide- und Eckzahn, bei einem Fötus von $20 \mathrm{~mm}$ länge auch now am 1. Nolar begann. Wis be- 
obachtete bei einem fötus von $36.5 \mathrm{~mm}$ Länge die Glockenform am 2 . Molar. Unser Befund weicht also von der Lehre ORBÁNs (1928) ab, daßs die Zahnanlage nicht aus der Zahnleiste, sondern zugleich mit dieser unmittelbar aus dem Deckepithel der Mundhöhle entstehe.

f) Vergleich der Reihenfolge der Zahnkeimentstehung mit der des Zahndurchbruchs.

Man vergleiche die Reihenfolge der Entstehung der Zahnkeime (Tabelle 3) und die des schon bekannten Durchbruchs der Zähne (Tabelle 4). Sie stimmen, abgesehen von dem Eckzahn und dem 1. Molar, fast miteinander überein (s. Tabelle 5).

Tabelle 3. Die Reihenfolge der Entstehung der Zähne.

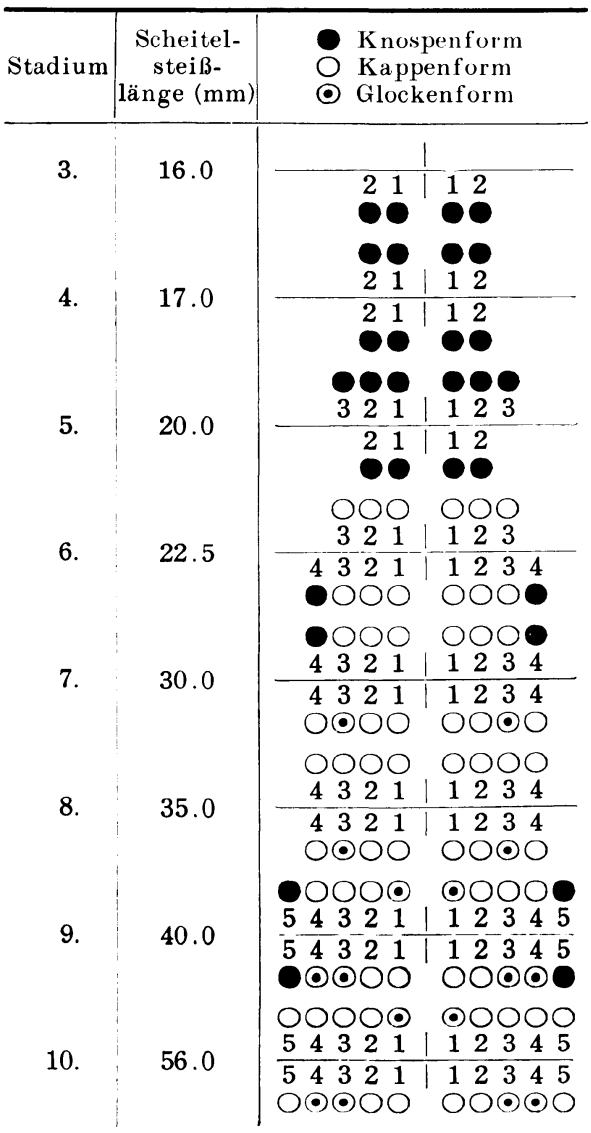

Tabelle 4. Die bekannte Reihenfolge des Durchbruchs der Zähne.

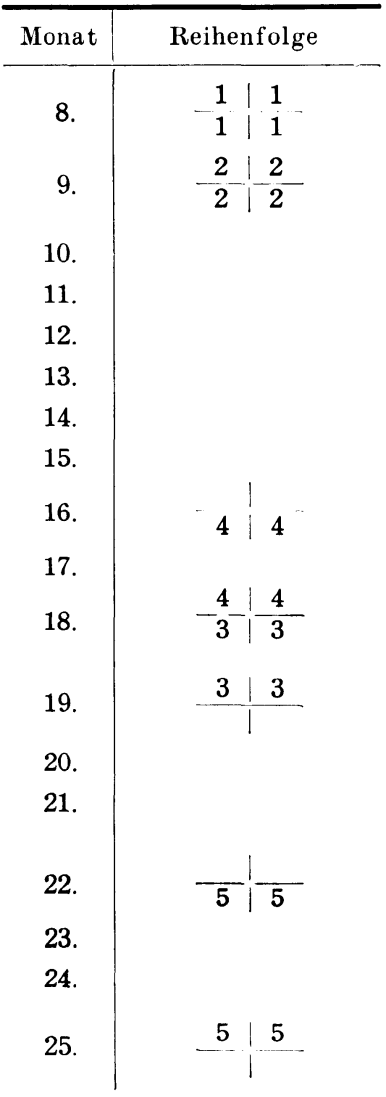


Tabelle 5. Der Vergleich der Reihenfolge des Entstehens der Zahnkeime mit der des Durchbruchs der Zähne.

\begin{tabular}{|c|c|c|c|c|}
\hline \multirow{2}{*}{$\begin{array}{l}\text { Reihen- } \\
\text { folge }\end{array}$} & \multicolumn{2}{|c|}{ Entstehen d. Zahnkeime } & \multicolumn{2}{|c|}{ Durchbruch d. Zähne } \\
\hline & Oberkiefer & Unterkiefer & Oberkiefer & Unterkiefer \\
\hline & $1 \mid 1$ & & $1 \mid 1$ & \\
\hline 1. & & \begin{tabular}{l|l}
1 & 1
\end{tabular} & & $1 \mid 1$ \\
\hline & $2 \mid 2$ & & $2 \mid 2$ & \\
\hline 2. & & $2 \mid 2$ & & $2 \mid 2$ \\
\hline 3 & $3 \mid 3$ & & $4 \mid 4$ & \\
\hline 3. & & $3 \mid 3$ & & \begin{tabular}{l|l}
4 & 4
\end{tabular} \\
\hline 4 & $4 \mid 4$ & & $3 \mid 3$ & \\
\hline & & $8=$ & & \\
\hline 5. & $5 \mid 5$ & \begin{tabular}{l|l}
5 & 5
\end{tabular} & \begin{tabular}{l|l}
5 & 5 \\
\end{tabular} & \begin{tabular}{l|l}
5 & 5
\end{tabular} \\
\hline
\end{tabular}

g) Die Form und die Lage der Zahnkeime.

Die Öffinung des schüsselartigen Schmelzorgans richtet sich vor€́rst schief nach vorn, schief nach außen usw., aber sie wird nachher nicht schief, sondern senkrecht.

In den beiden Kiefern entstehen die 4 Keime der Eck- und Schneidezähne fast in gleichem Abstand, der Keim der 1. Molar entsteht aber auf der distalen Seite in einem größeren Abstand. Der 2. Molarenkeim entsteht ebensoweit distal.

Jeder Zahnkeim tritt beim Fötus von bis zu $56 \mathrm{~mm}$ Länge in Ellipsoidform auf und ist in proximodistaler Richtung breiter. Er erinnert noch nicht an die Form der eigentlichen Zahnkrone.

\section{h) Das ACKERKNECHTsche Organ.}

ACKERKNECHT (1912) fand bei einigen Ungulaten und Raubtieren an der Kiefersymphyse dicht hinter den vordersten Unterkieferzähnen eine solide zapfenartige oder auch kurze röhrenförmige Einsenkung des Schleimhautepithels. Dieses Gebilde ist seitdem unter dem Namen, ACKERKNECHTsches Organ, bekannt. Weitere Untersuchungen ergaben, daß das Organ in vielen Sängetieren vorkommt, aber nicht immer. EBERLE (1925) glaubte es auch bei zwei älteren menschlichen Föten gefunden zu haben. NISHIYAMA (1933) konnte das Organ bei den Herrentieren and dem Menschen nicht finden. Nach KATO (1953) erscheint es beim $13 \mathrm{~mm}$ langen Fötus als winziger Vorsprung und verschwindet bald und ist beim Fötus von $27 \mathrm{~mm}$ Länge nicht zu finden. Nach seiner Meinung erscheine es beim Fötus des Japaners etwas früher als bei dem des Europïers, um auch früher zu verschwinden. Das Organ wird als Rest einer Drüse ange- 
nommen.

Ich fand das Organ erst beim $16 \mathrm{~mm}$ langen Fötus, ebenso auch beim $30 \mathrm{~mm}$ langen Fötus kurz vor dem Verschwinden. Bei älteren Föten ließ sich aber keine Spur des Organs bemerken.

\section{i) Die Lippenfurchenleiste.}

Beim Embryo in der Länge von $16 \mathrm{~mm}$ teilt sich der freie Saum der Zahnleiste in der Gegend des künftigen Eck- und Molarenteils in ein lippenseitiges und ein wangenseitiges Blatt, welch letzteres sich als die Lippenfurchenleiste entwickelt. Sie ist dicker als die lippenseitige Zahnleiste. Ihre Zellen sind weniger dicht vorhanden als in der Zahnleiste.

Diese Lippenfurchenleiste wird beim $18 \mathrm{~mm}$ langen Fötus vorn von dem Eckzahnteil ab immer niedriger, hinten aber läuft sie neben der Zahnleiste, und ihr Ende biegt sich nicht buccalwärts.

Die Lippenfurchenleiste stellt sich in den beiden Kiefern zu dem Deckepithel senkrecht und geht weniger tief in das Bindegewebe als die Zahnleiste. Sie ist im Oberkiefer der Zahnleiste näher als im Unterkiefer. Beim $30 \mathrm{~mm}$ langen Fötus reicht sie am Eckzahnteil am tiefsten. Die Lippenfurchenleiste zeigt sich neben jedem Zahnkeim etwas besser entwickelt als an den dazwischen liegenden Anteilen.

\section{Zusammenfassung.}

a) Die Zahnleiste.

1. Sie erscheint zuerst beim Fötus von $10 \mathrm{~mm}$ Scheitelsteißlänge am Molarenteil des Unterkiefers, früher als das Auftreten des MECKELKnorpels. Im Oberkiefer erscheint die Zahnleiste erst beim $16 \mathrm{~mm}$ langen Fötus.

2. Sie neigt sich bekanntlich bald nach ihrem Entstehen lingualwärts. Der Grad der Neigung ist im Oberkiefer stärker als im Unterkiefer und ist in den beiden Kiefern am Vorderzahnteil stärker als am Molarenteil. Beim $40 \mathrm{~mm}$ langen Fötus läßt die immer noch lingualwärts geneigte Zahnleiste ihren Saum auf die buccale Seite hin biegen.

3. Die Zahnleiste des Unterkiefers krümmt sich an dem hinteren Teil $30^{\circ}$ gegen die Wange zu, welche Biegung im Fötus von $40 \mathrm{~mm}$ Länge wieder abnimmt.

4. Der Bogen, den die Zahnleiste als ganzes darstellt, ist im Oberkiefer größer als im Unterkiefer, so daß die Zahnleiste das Oberkiefers außerhalb derjenigen des Unterkiefers sitzt. Dieses Verhältnis ist beim $30 \mathrm{~mm}$ langen Fötus am auffallendsten, wird aber später immer unbedeutender.

b) Die Zahnkeime.

1. Beim 16-16.5 mm langen Fötus lassen sich im Unterkiefer 4 
Schneidezahnkeime erkennen, im Oberkiefer aber erst beim 17-18 mm langen Fötus.

2. Der Eckzahnkeim des Oberkiefers erscheint erst mit der Scheitelsteißlänge von $20 \mathrm{~mm}$, und der Eckzahn- und der erste Molarenkeim mit der Länge von $23 \mathrm{~mm}$, aber der erste Molarenkeim des Oberkiefers und der zweite Molarenkeim der beiden Kiefer mit der Länge von $30 \mathrm{~mm}$.

3. Der Zahnkeim, der im Saum der Zahnleiste erschienen ist, entwickelt sich schräg auf der lingualen Seite der Zahnleiste. Die Reihenfolge der Entstehung der Zahnkeime deckt sich im großen und ganzen mit der jenigen des Durchbruchs der Zähne nach der Geburt, ausgenommen der Eckzahnkeim, der vor dem Molarenkeim entsteht.

4. Das kappenförmige Schmelzorgan verlängert sich anfangs ganz unbestimmt schräg lingual- oder buccinalwärts, aber in den Föten, deren Länge größer ist als $30-56 \mathrm{~mm}$, in der Richtung der Längsachse der Zahnwurzel.

5. Die Zahnkeime bewahren im Kappen- und Glockenstadium eine in der Wangen-Zungenrichtung ein wenig gepresste Form.

c) Das ACKERKNECHTsche Organ.

Das Organ läßt sich erst bei dem $16 \mathrm{~mm}$ langen Fötus neben der medialen Ebene auf der hinteren Fläche der Zahnleiste als ein kleiner Vorsprung bemerken. Beim $30 \mathrm{~mm}$ langen Fötus wird es schon rudimentär und beim $32 \mathrm{~mm}$ langen nicht mehr gefunden.

d) Die Lippenfurchenleiste.

1. Diese Leiste kommt beim Fötus von $16 \mathrm{~mm}$ Länge auf der Lippenseite des Eck- und Molarenteil der Zahnleiste herver und zwar, wie diese, aus dem Deckenepithel der Mundhöhle. Sie geht immer tiefer in das Bindegewebe hinein, ohne daß sie wie die Zahnleiste sich lingualwärts hin böge. Die Lippenfurchenleiste ist dicker als die Zahnleiste, aber ihre Zellen sind weniger dicht vorhanden.

2. Der hintere Teil der Lippenfurchenleiste biegt sich im Gegenteil zu der Zahnleiste nicht nach außen.

3. Sie ist beim $30 \mathrm{~mm}$ langen Fötus in den beiden Kiefern am Eckzahnteil am tiefsten. Sie ist im Oberkiefer näher von der Zahnleiste begleitet als im Unterkiefer.

\section{内 容 自 抄.}

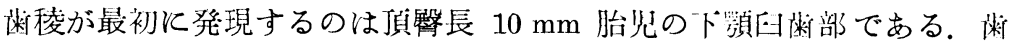
稜は発生後まもなく舌側飞傾く，頂臂長 $40 \mathrm{~mm}$ 胎児に至ると米稜は舌側 に傾斜したまま更に其の先端が煩側に傾斜する。下顎歯秓は後部の 1 所で

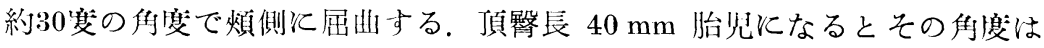

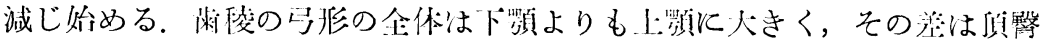




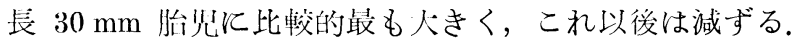

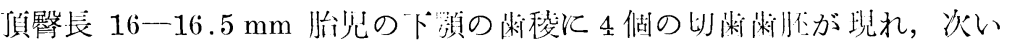

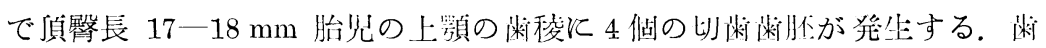

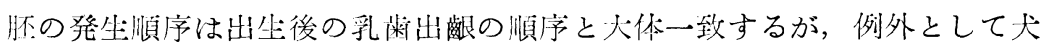

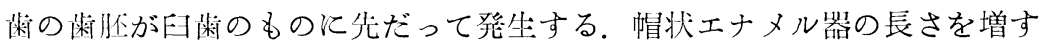
方向は初めは一定せず，或は舌側飞或は煩側に向うが，頂臂長 30-56 mm 胎児になると，みな彝根長軸の方向に向う。歯肧は帽状期と鐘状期を通じ て唇舌の方向に生せられた形をとる.

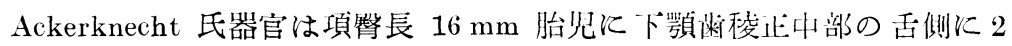
個の微弱な隆起として現われるが，項照長 $30 \mathrm{~mm}$ 胎児には痕跡状となり， $32 \mathrm{~mm}$ 胎児以後では認められなかった。

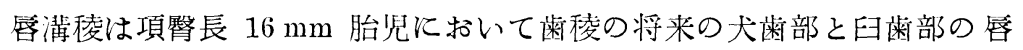
側に現れ，歯稜のように舌側に傾斜しない，そして唇满稜の後部は歯棱の 後部のように㚘側に曲らない。唇满稜は頂腎長 $30 \mathrm{~mm}$ 胎児では上下㖽と もに犬歯部で最も深い。唇瑇棱の歯肧に対する部分は少し肥厚する.

\section{Literatur.}

Ackerknecht, E. : Ein eigenartiges Organ im Mundhöhlenboden der Säugetiere. Anat. Anz. 41 (1912). - Eberle, W.: Zur Entwicklung des Ackerknechtschen Organs. Diss. med.-vet. Zürich. 1925. Zit. n. Bolk u. a.: Handbuch der vergleichenden Anatomie der Wirbeltiere. Bd. 3. 1937. - Kollmann, J. : Handatlas der Entwicklungsgeschichte des Menschen. Bd. 2. Jena, 1907. -- Kato, K.: Embryological studies on the development of the tooth in human embryo, with special reference to the formation of the tooth band and the lip furrow band. (jap. m. engl. Zfass.) Shigaku 41 (1953). - Meyer, W. : Lehrbuch der normalen Histologie und Entwicklungsgeschichte der Zähne des Menschen. Bd. 1. München, 1932. - Nishiyama, Y.: Beiträge zur Kenntnis der Morphologie und Entwicklung des Ackerknechtschen Organs. Keijo J. Med. 4 (1933). - Orban, B. Entwicklung und Wachstum der Zahnleiste und Zahnkeime. Z. Anat. 85 (1982). - Röse, C. : Über die Entwicklung der Zähne des Menschen. Arch. mikr. Anat. 38 (1891). - Über die erste Anlage der Zahnleiste beim Menschen. Anat. Anz. 8 (1893). - Watanabe, T.: Über die Entwicklung des Unterkiefers bei japanischen Embryos, besonders über die Entwicklung der Zähne und Alveolen. (Jap.) Shikagakuho. 42 (1937). - Yamamura, Sh.: Beitrag zur Studie über die Entwicklung des Schmelzorgans der Zähne des Menschen. Shikagakuho 17 (1937).

\section{Erklarung der Tafelabbildungen.}

$A-O$ ACKERKNECHTsches Organ, $c$ Keim des Eckzahnes, $i_{1}$ Keim des mittleren Schneidzahnes, $i_{2}$ Keim des seitlichen Schneidzahnes, $K n$ Knochen, $L$ Lippe, Le Lippenepithel, Lf Lippenfurche, $L f l$ Lippenfurchenleiste, $M h$ Mundhöhle, 
$M-k$ MECKELscher Knorpel, $m_{1}$ Keim des ersten Molarn, $m_{2}$ Keim des zweiten Molarn, $\mathrm{Nl}$ Nebenleiste, $\mathrm{Nm}$ Nervus mandibularis, Olf Oberkiefer, prZl Primitive Zahnleiste, $\$ \$ k n$ Schmelzknoten, Subl Sublingualdrüse, Subm Submandibulardrüse, Ukf Unterkiefer, $Z$ Zunge, Zl Zahnleiste.

Tafelabb. 1. Unterkiefer. Fötus von $10 \mathrm{~mm}$ Scheitelsteißlänge. Von unten. Etwa $20 \times$.

Tafelabb. 2. Unterkiefer. Fötus von $16 \mathrm{~mm}$ Scheitelsteißlänge. Von unten. Die Zahnleiste neigt sich lingualwärts. Etwa $20 \times$.

Tafelabb. 3. Oberkiefer. Fötus von $16 \mathrm{~mm}$ Scheitelsteißlänge. Von oben. Etwa $20 \times$.

Tafelabb. 4. Unterkiefer. Fötus von $17 \mathrm{~mm}$ Scheitelsteißlänge. Von unten. Etwa $20 \times$.

Tafelabb. 5. Oberkiefer. Fötus von $17 \mathrm{~mm}$ Scheitelsteißlänge. Von oben. Etwa $20 \times$.

Tafelabb. 6. Unterkiefer. Fötus von $20 \mathrm{~mm}$ Scheitelsteißlänge von unter. Etwa $20 \times$.

Tafelabb. 7. Oberkiefer. Fötus von $20 \mathrm{~mm}$ Scheitelsteißlänge. Von oben. Etwa $20 \times$.

Tafelabb. 8. Unterkiefer. Fötus von $23 \mathrm{~mm}$ Scheitelsteißlänge. Von unten. Etwa $20 \times$.

Tafelabb. 9. Oberkiefer. Fötus von $23 \mathrm{~mm}$ Scheitelsteißlänge. Von oben. Etwa $20 \times$.

Tafelabb. 10. Unterkiefer. Fötus von $30 \mathrm{~mm}$ Scheitelsteißlänge. Von unten. Etwa $20 \times$.

Tafelabb. 11. Oberkiefer. Fötus von $30 \mathrm{~mm}$ Scheitelsteißlänge. Von oben. Etwa $20 \times$.

Tafelabb. 12. Unterkiefer. Fötus von $35 \mathrm{~mm}$ Scheitelsteißlänge. Von unten. Etwa $20 \times$.

Tafelabb. 13. Oberkiefer. Fötus von $35 \mathrm{~mm}$ Scheitelsteißlänge. Von oben. Etwa $20 \times$.

Tafelabb. 14. Unterkiefer. Fötus von $40 \mathrm{~mm}$ Scheitelsteißlänge. Von unten. Etwa $20 \times$.

Tafelabb. 15. Oberkiefer. Fötus von $40 \mathrm{~mm}$ Scheitelsteißlänge. Von oben. Etwa $20 \times$.

Tafelabb. 16. Unterkiefer. Fötus von $56 \mathrm{~mm}$ Scheitelsteißlänge. Von unten. Etwa $20 \times$.

Tafelabb. 17. Oberkiefer. Fötus von $56 \mathrm{~mm}$ Scheitelsteißlänge. Von oben. Etwa $20 \times$.

Tafelabb. 18. Die anfangs lingualwärts (d. h. innen), dann buccalwärts (d. h. außen) geneigte Zahnleiste. Der Zahnkeim ist im Stadium des Übergangs von der Kappenform in die Glockenform. Fötus von $40 \mathrm{~mm}$ Scheitelsteißlänge. 
G. KAGAWA (1)
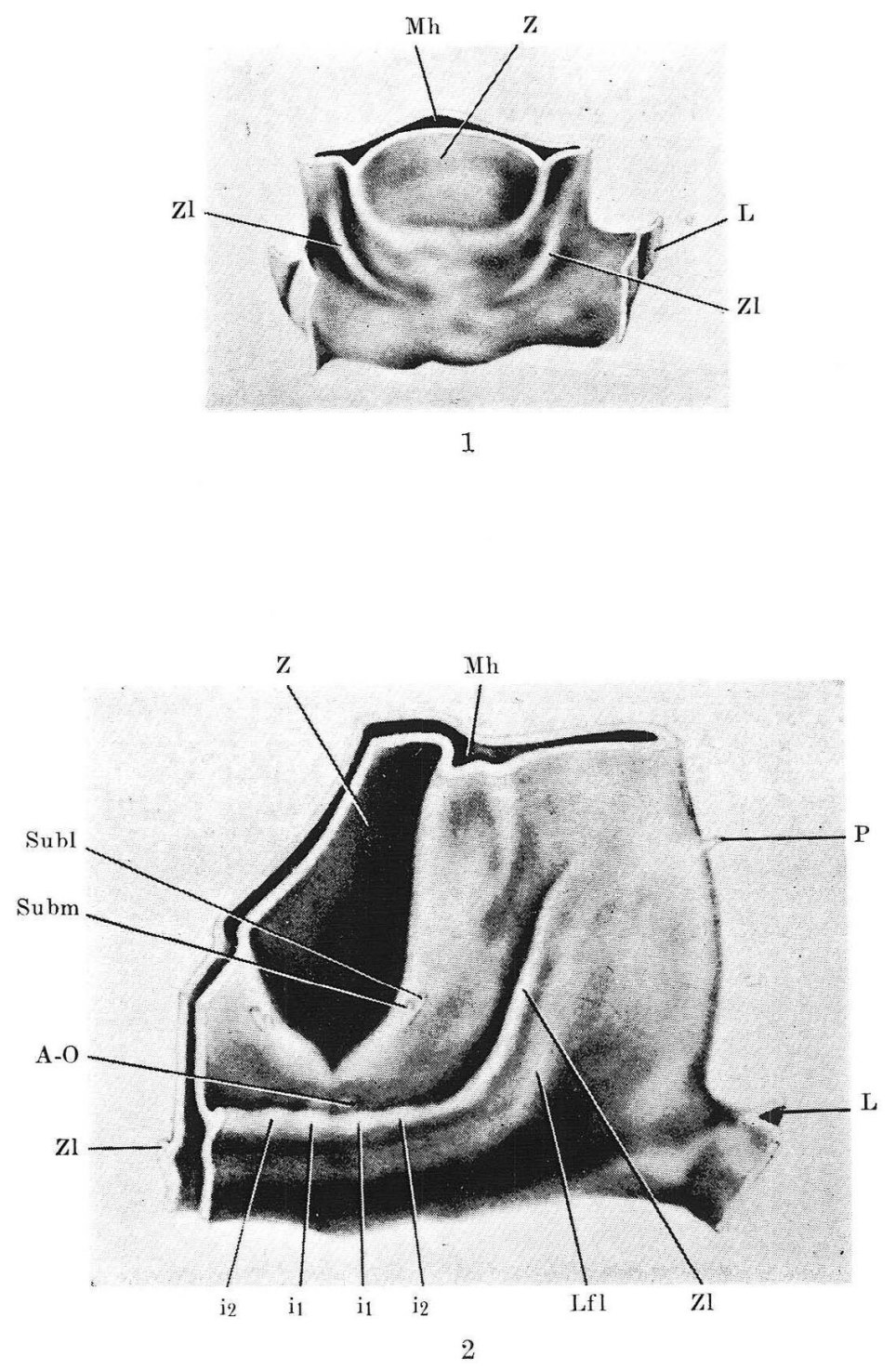
G, KAGAWA (2)
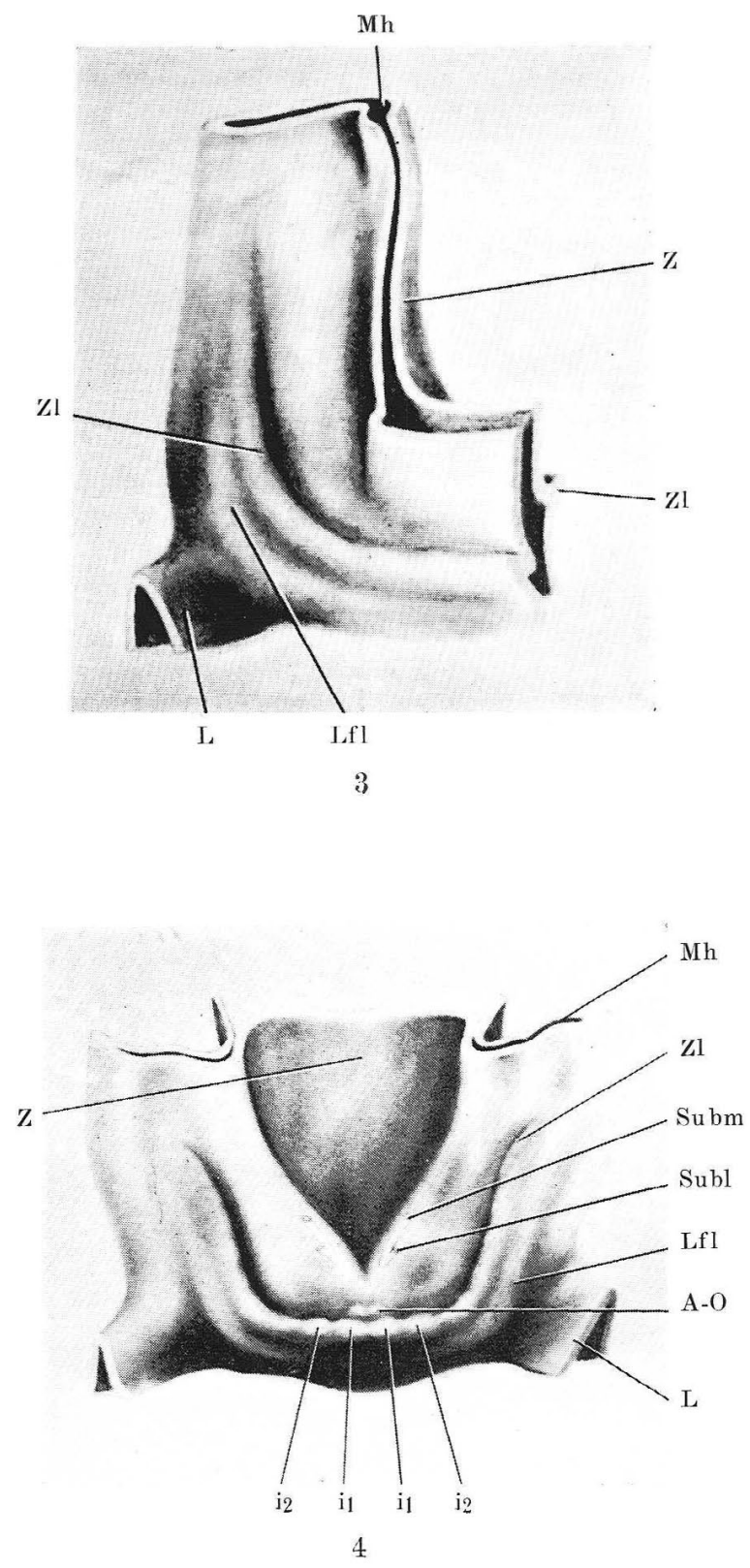


\section{G, KACAWA (3)}
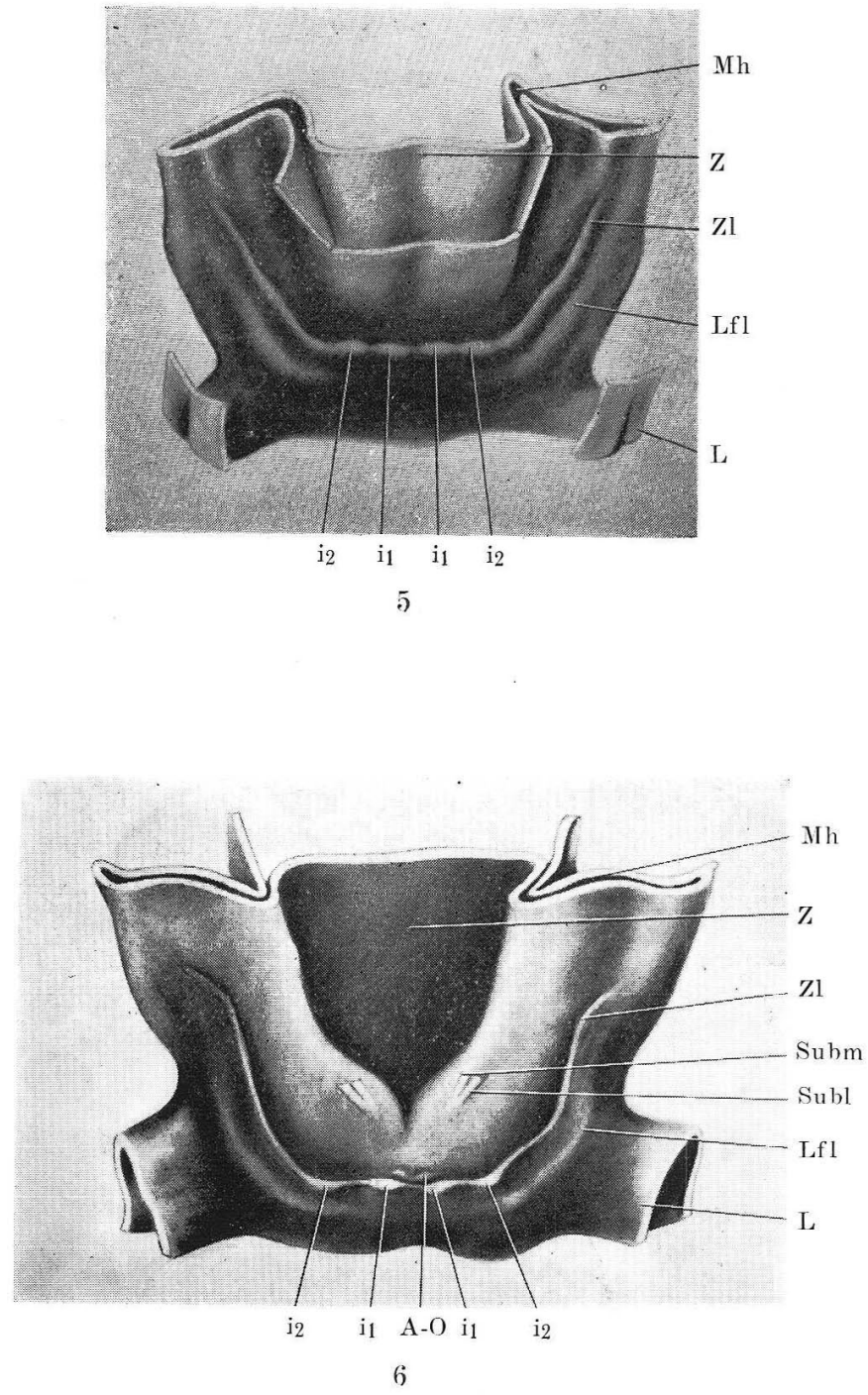
G. KAGAWA (4)
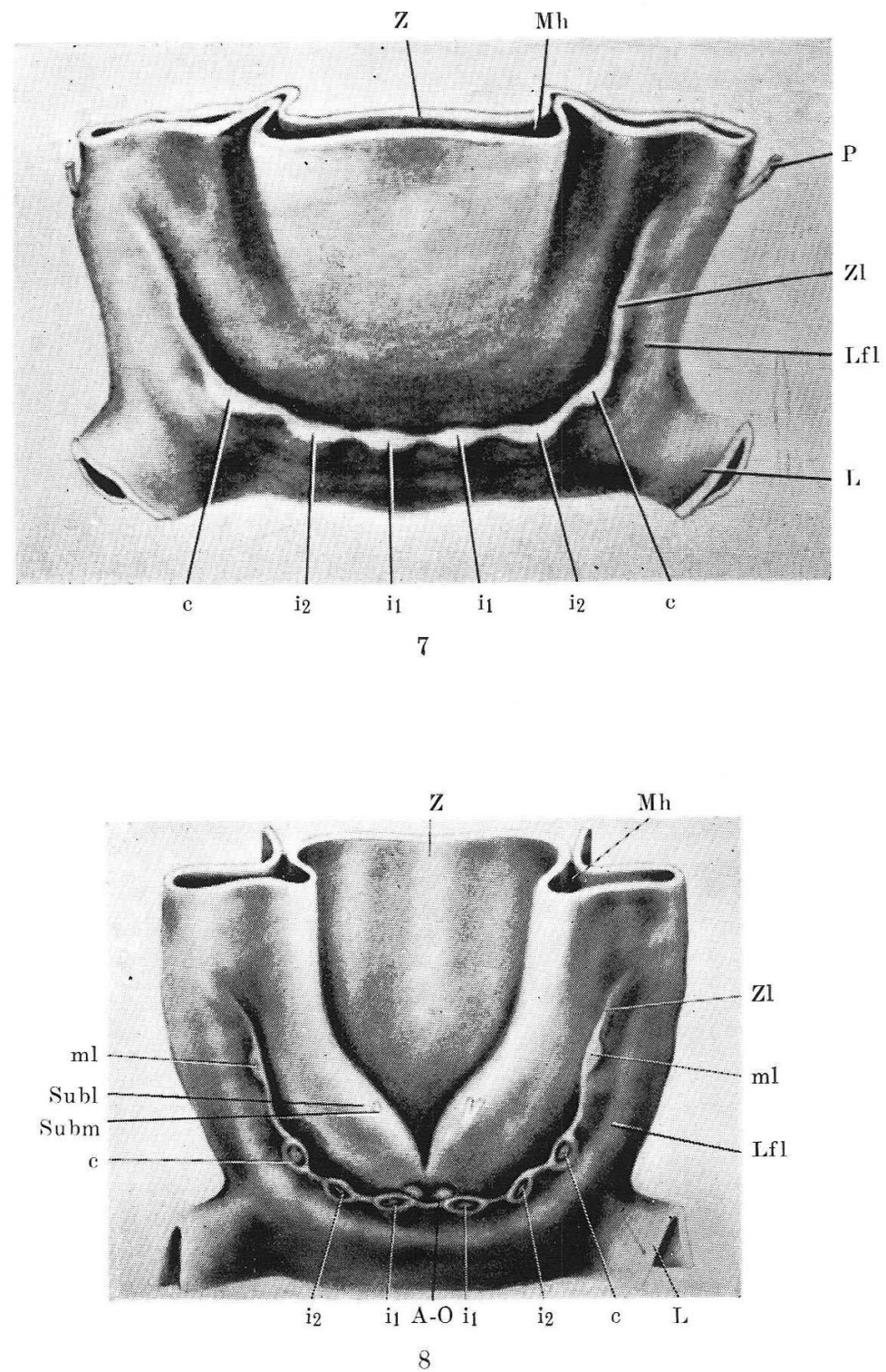


\section{G. KAGAWA (5)}
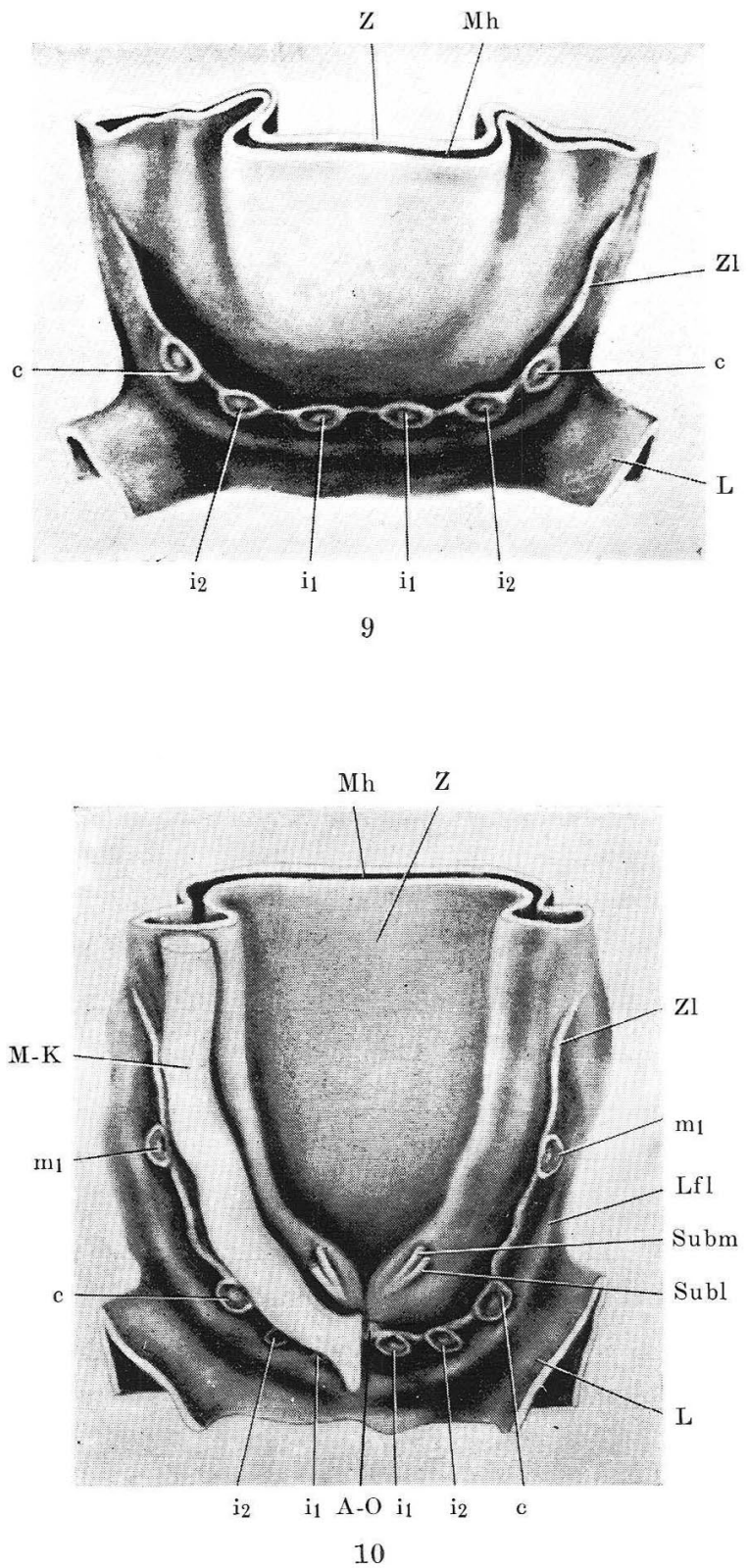
G. KAGAWA (6)
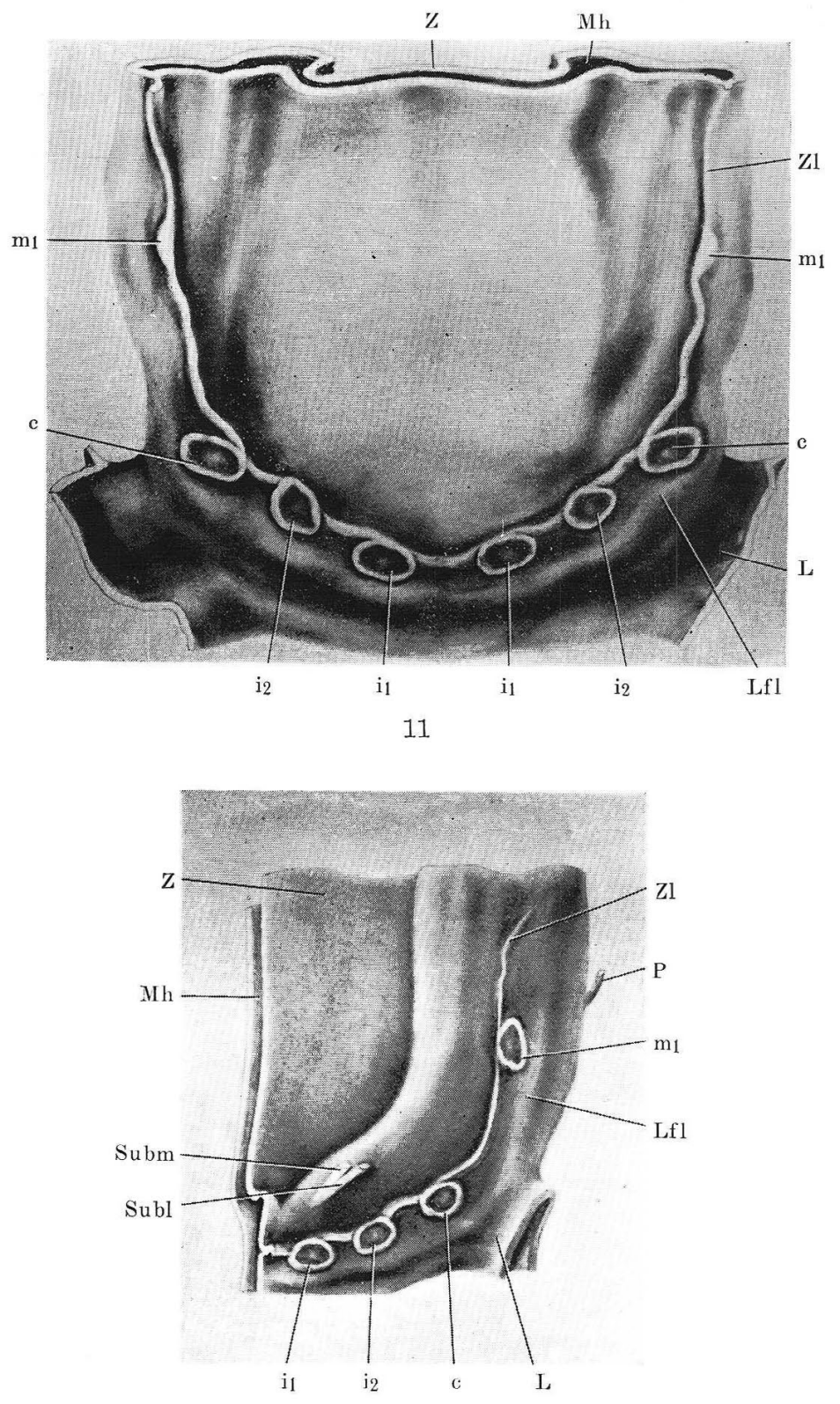

12 


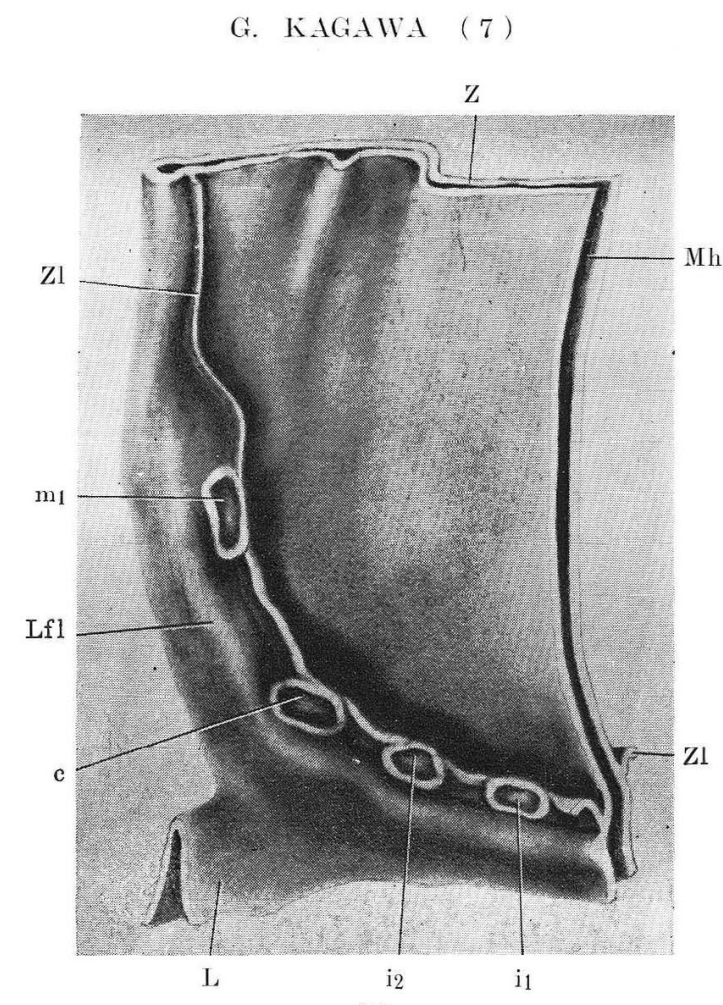

13

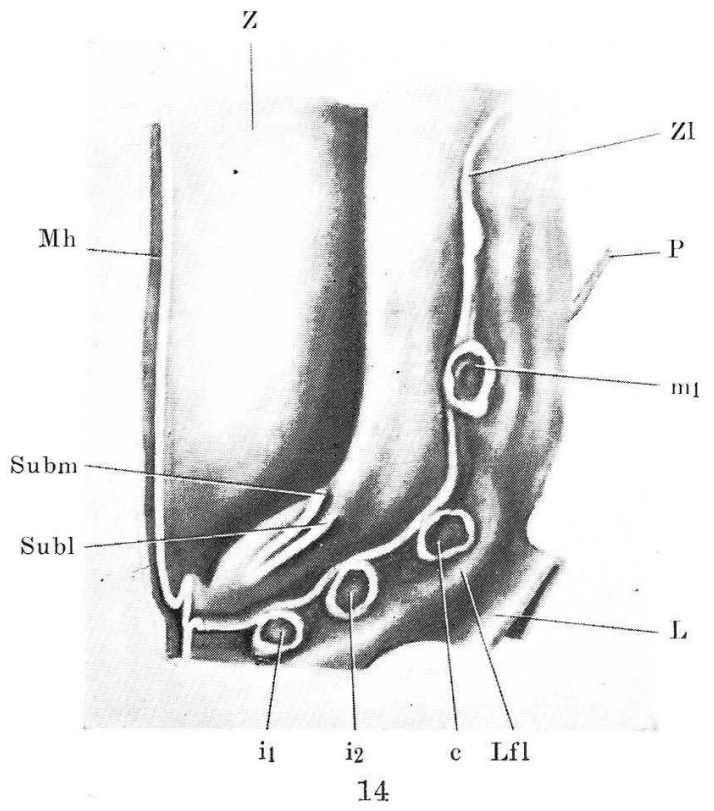

515 
G. KAGAWA (8)

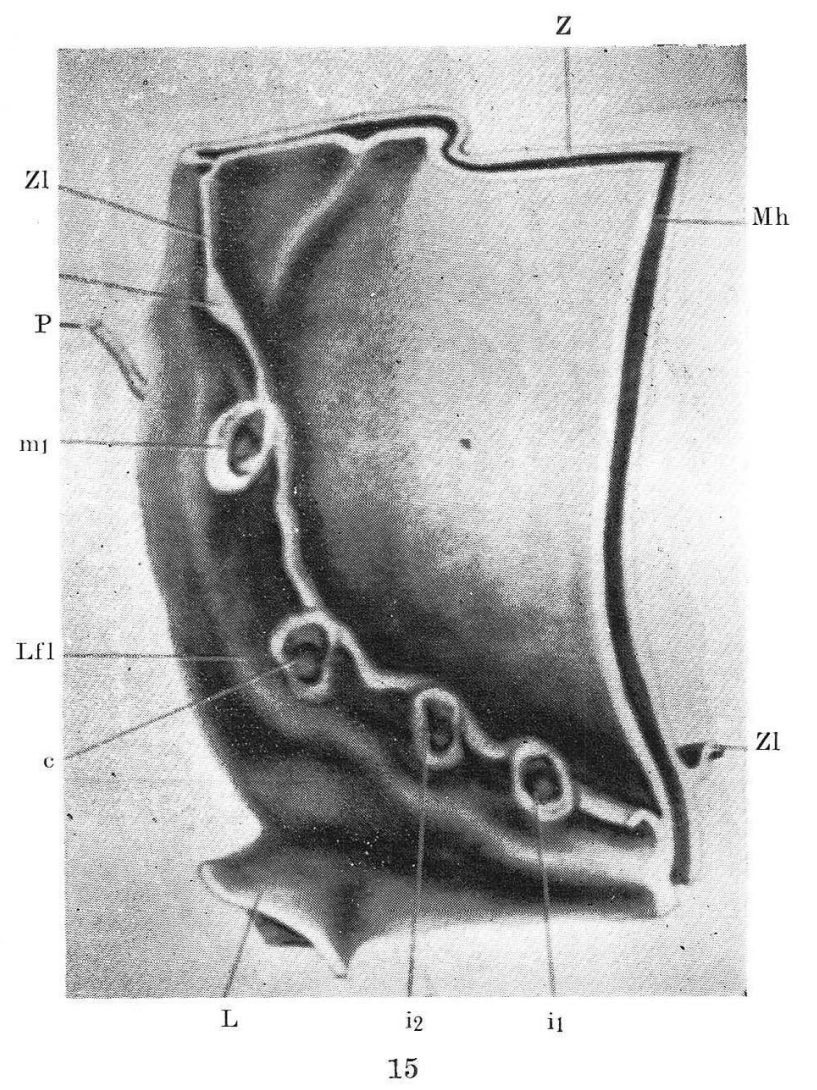


G. KAGAWA (9)

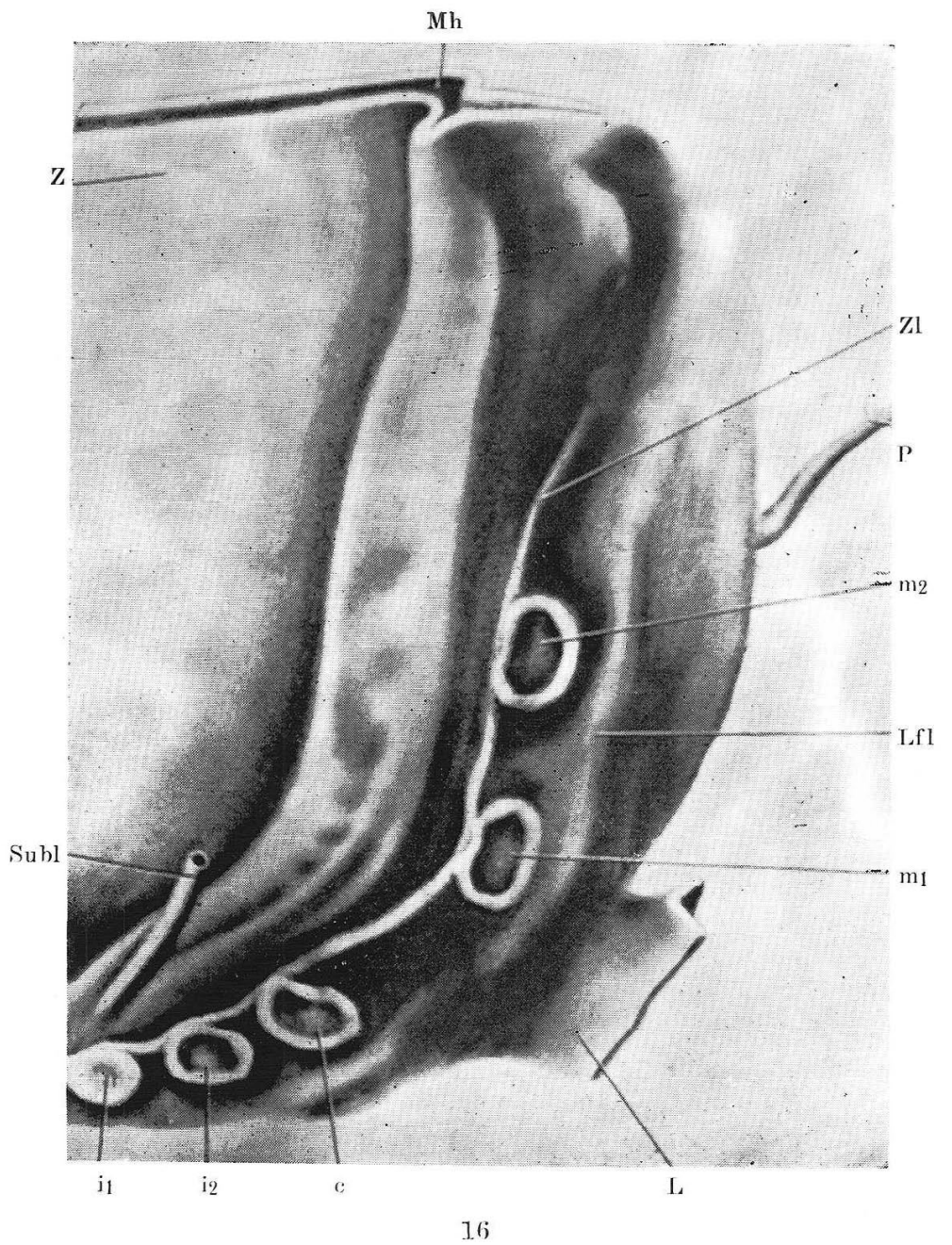


G. KARAWA (10)

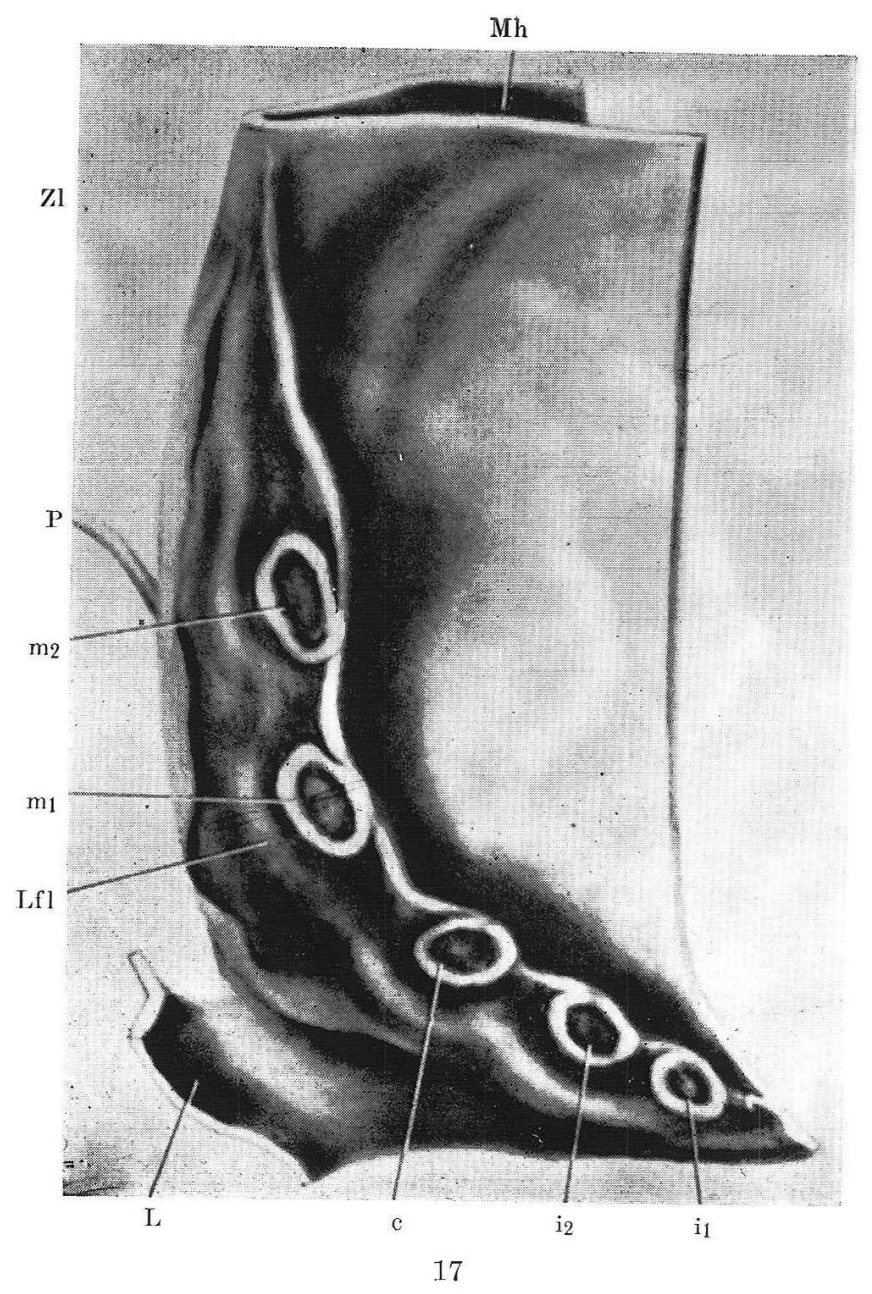


G. KAGAWA (11)

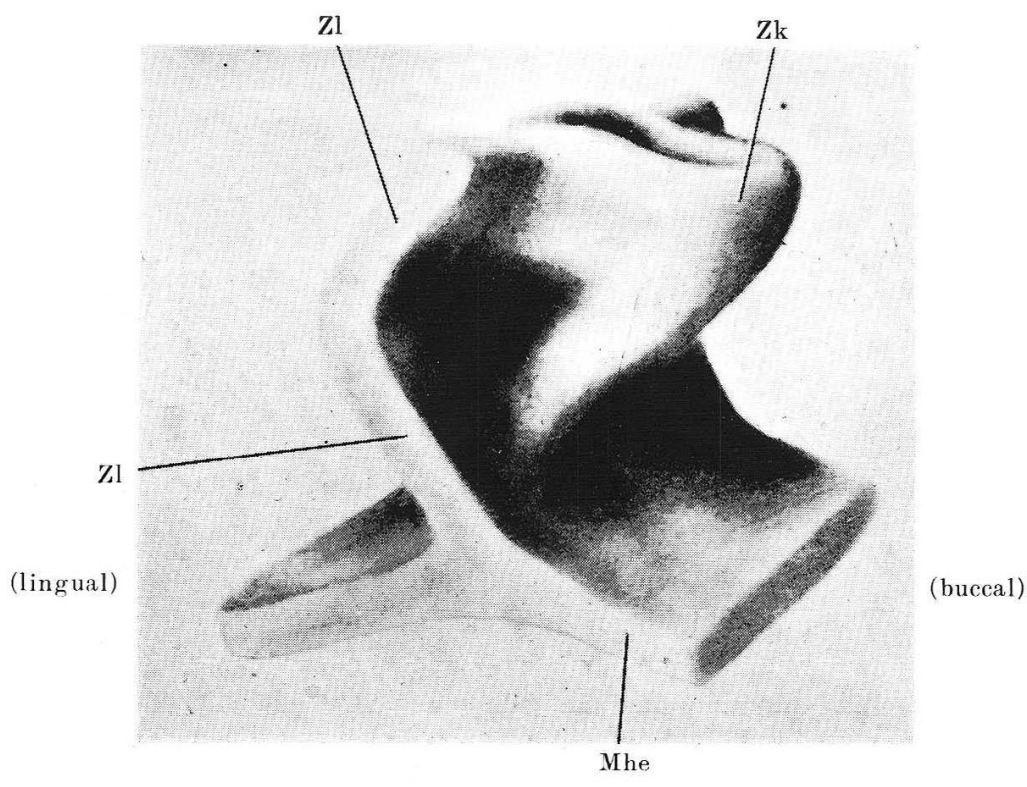

18

523 